\title{
The public remain uninformed and wary of climate engineering
}

\author{
Daniel P. Carlisle*
}

$\mathrm{PhD}$ Student, School of Communication, Journalism and Marketing

Massey University, Tennent Drive, Palmerston North, 4410

NEW ZEALAND

D.Carlisle@massey.ac.nz

ORCID: 0000-0003-4387-4405

Pamela M. Feetham

Lecturer, School of Communication, Journalism and Marketing

Massey University, Tennent Drive, Palmerston North, 4410

NEW ZEALAND

P.M.Feetham@massey.ac.nz

ORCID: 0000-0001-8628-9973

Malcolm J. Wright

Professor, School of Communication Journalism and Marketing

Massey University, Dairy Flat Highway, Albany, Auckland, 0632

NEW ZEALAND

Adjunct Professor, Ehrenberg-Bass Institute for Marketing Science**

University of South Australia, North Terrace, Adelaide, South Australia 5000

AUSTRALIA

Malcolm.Wright@marketingscience.info

Damon A.H. Teagle

Professor, School of Ocean \& Earth Science, National Oceanography Centre Southampton

University of Southampton, European Way, Southampton, SO14-3ZH

UNITED KINGDOM

Damon.Teagle@southampton.ac.uk

* Corresponding Author

** Secondary affiliation for Malcolm Wright 
Abstract: International $\mathrm{CO}_{2}$ emissions reduction commitments are insufficient to avert damaging global warming and imperil a sustainable future. Climate engineering approaches are increasingly proposed as near-term intervention strategies, but deployment of these controversial techniques will require careful engagement with and the support of the public. New quantitative measurements of public perceptions for six climate engineering approaches show that the public of the United Kingdom (UK), United States (US), Australia (AU), and New Zealand (NZ) continue to have little knowledge of climate engineering. All approaches are regarded unfavourably, albeit less so for Carbon Dioxide Removal (CDR) than Solar Radiation Management (SRM). Knowledge and perceptions are remarkably similar between countries although UK and US respondents are more favourable towards SRM and UK respondents are more favourable towards CDR. Stratospheric Aerosol Injection is the most negatively perceived approach. Support for small-scale trials is also higher for CDR approaches than SRM. Statistical analyses yield mixed relationships between perceptions of climate engineering and age, political affiliation and pro-ecological views. Thus far, attempts to engage the public with climate engineering have seen little change over time and consequently, there is growing urgency to facilitate careful citizen deliberation using objective and instructive information about climate engineering.

Keywords: Public Engagement, Climate Engineering, Geoengineering, Cross-country, Framing Effects 


\section{Introduction}

Following COP 21 in Paris, 194 nations agreed to limit future global warming to less than $2^{\circ} \mathrm{C}$ above pre-industrial levels, although $<1.5^{\circ} \mathrm{C}$ is a preferred target for many nations. These 194 nations face significant challenges and decisions on their pathways to reducing greenhouse gas emissions. The agreed actions to date are insufficient to achieve the targets (Bawden 2016; Lawrence et al. 2018; Schleussner et al. 2016) with the current Paris pledges providing less than half the emissions reductions required (UNEP 2018). Many national Net-Zero ambitions rely on substantial negative emissions to balance $\mathrm{CO}_{2}$ inputs from difficult to decarbonise sectors (e.g., cement, land-use, shipping, air travel), but remain imprecise about how this $\mathrm{CO}_{2}$-drawdown will be achieved. The unlikelihood of reaching the Paris goals through mitigation alone has prompted new calls for globally governed research into potential large-scale climate engineering approaches (Bellamy and Healey 2018; Biermann and Möller 2019; Ki-moon 2019) including Carbon Dioxide Removal (CDR) approaches that sequester atmospheric carbon dioxide and Solar Radiation Management (SRM) methods that alter the radiative forcing of Earth's atmosphere (Horton 2015; Lawrence et al. 2018).

Researchers worldwide report on-going technological advances and continue to develop knowledge of climate engineering feasibility and impacts (Irvine et al. 2019; Lawrence et al. 2018; MacMartin et al. 2018; Royal Society and Royal Academy of Engineering 2018; Salter et al. 2014; Smith et al. 2018). Initiatives such as the Geoengineering Model Inter-comparison Project (GeoMIP) allow scientists to conduct multiple climate modelling simulations to estimate the likely global impacts of particular climate interventions (Kravitz et al. 2019; Kravitz et al. 2018). Interest is also building in the Harvard based Stratospheric Controlled Perturbation Experiment (SCoPEx) project that would release aerosols from a balloon to study aerosol physics and chemistry related to some SRM approaches. Following the 2012 withdrawal of the similar UK based 'SPICE' project, SCoPEx would be the first explicit field test of SRM technologies (Tollefson 2018). Currently, uncertainty remains around the global impacts of climate engineering as most research is restricted to computer modelling or controlled laboratory settings (Lawrence et al. 2018). Scientists are also careful to point out that climate engineering is not a panacea for failure to achieve emissions reductions, and must be 
deployed in concert with, rather than a distraction from accelerated improvements in energy efficiency and greenhouse gas emissions reduction efforts (Royal Society and Royal Academy of Engineering 2018).

The warnings for more action on Paris Agreement targets highlight the urgency for researchers and policy makers to engage the public in the development of potential solutions including climate engineering approaches (Burns et al. 2016; Rayner et al. 2013) before societies are confronted with the necessity of deploying such techniques at scale. Despite increasing research on public perceptions of climate engineering (Cummings et al. 2017) there are still substantial gaps in the literature. Few studies investigate public perceptions outside of developed nations in the northern hemisphere (Burns et al. 2016) or over time (Braun et al. 2018b).

The present quantitative work, therefore, examines public perceptions of climate engineering in surveys conducted across four countries and innovatively, over time. It is the first study to systematically measure public perceptions from surveys conducted in the United Kingdom (UK), United States (US), Australia (AU) and New Zealand (NZ) in December 2018, against previous measurements derived from surveys conducted in AU and NZ in December 2012 (Wright et al. 2014). The method draws on well-established psychological theory and marketing techniques to elicit and measure cognitive associations with new product concepts or brands (Anderson 1983; Anderson and Bower 1974; Romaniuk 2013; Wright et al. 2014). The present work substantively expanded the original study with fresh fieldwork that drew on new knowledge and technological advancements within the field of climate engineering, as well as further understanding of framing effects raised in recent literature. We also examine the associations with demographics, ecological views and political party affiliation on public perceptions of climate engineering and whether the public would support small scale trials for each of the six approaches. The resulting analysis provides a robust system that quantifies public perceptions of climate engineering and provides a benchmark for future comparisons of public opinions by sampling across multiple countries and over time. Tracking public opinion, whether changed or stagnant, over time provides imperative information for policy makers and those 
organisations responsible for collaborating and communicating with the public on potential climate solutions.

\subsection{Public engagement with emerging technologies}

Public engagement is increasingly sought as a key element of the governance of emerging science and technology. Over the years, three key arguments have emerged to promote public participation (Chilvers 2009; Fiorino 1990; Stirling 2008; Wilsdon and Willis 2004; Winickoff et al. 2015). The normative rationale suggests public participation is necessary in democracy and that the public have a right to be involved in policy that will affect them. The substantive rationale claims that public participation can improve decision-making and outcomes by incorporating diverse knowledge and viewpoints. Finally, the instrumental rationale suggests participation can achieve specific outcomes including increasing trust in science, enhancing legitimacy of institutions, and avoiding conflict. The latter substantive and instrumental outcomes are rarely evidenced in practice (Chilvers 2009), leading to the question of what value public participation might provide beyond the tokenistic attempts at democracy. Nonetheless, the growing impetus for public engagement with science is apparent across a range of emerging technologies (Stirling 2008), such as nanotechnologies (Rogers-Hayden and Pidgeon 2007), and climate engineering (Bellamy and Lezaun 2017; Corner et al. 2012).

Social scientists also differentiate between three types of public engagement mechanisms (Rowe and Frewer 2005). Public Communication mechanisms involve a passive process where the public receive information, but do not play an active role in informing decision making; public consultation mechanisms, including the current study, are used to elicit opinions from the public; and public participation mechanisms involve dialogue between stakeholders and the public to share knowledge and negotiate understanding. Each of these types of public engagement have inherent flaws. One main criticism relates to public communication mechanisms and the 'deficit' model of science communication. The deficit model assumed that educating the public through communication mechanisms would improve citizens' perceptions of science (Corner and Pidgeon 2010).

Contemporary public consultation and public participation mechanisms reject the deficit model and 
imply citizens can make informed judgements in the absence of technical knowledge under the right conditions (Wilsdon and Willis 2004).

Given the global significance of climate engineering, large-scale public consultation methods, are needed to provide systematic measurement of public opinion across global populations.

Quantitative surveys address these needs but are typically restricted by narrow standardised measures of 'acceptance' or 'support'. These attitudinal measures are criticised for disregarding more nuanced positions and overlooking participants underlying reasoning. Accordingly, there is concern among social scientists that quantitative survey research may not reflect actual public opinion and could exclude legitimate policy alternatives from future consideration (Bellamy et al. 2012). One method of addressing these concerns are small-scale participatory mechanisms that encourage citizens to engage in nuanced discussions and challenge the underlying assumptions that shape the appraisal process. For example, Bellamy et al. (2016) report a deliberative appraisal method where participants developed their own appraisal criteria that better reflect the small groups' opinions on climate engineering proposals. To address these concerns, the current study draws on participative elements in an initial qualitative phase to identify a list of citizen-generated appraisal criteria that are later applied in the quantitative phase of public consultation.

\subsection{Framing the climate engineering debate}

Eliciting public opinion on emerging technologies is particularly challenging as citizens are often unfamiliar with the technologies in question. One issue is that survey instruments may elicit 'nonattitudes' where participants respond to questionnaire items despite holding no genuine prior opinion on the matter (Asher 2017). These non-attitude responses are often sensitive to minor changes in questionnaire wording and may distort measures of public opinion. Researchers have therefore raised concerns about the way climate engineering is framed during public engagement.

One framing concern is that CDR and SRM approaches should not be lumped together under the broad umbrella term 'climate engineering' as CDR approaches are substantially different from SRM (Heyward 2013; Lomax et al. 2015; Minx et al. 2018). CDR approaches share greater similarities with mitigation strategies that reduce atmospheric carbon concentrations, whereas SRM 
approaches do not (Minx et al. 2018). Another framing concern is that the higher risk profile of SRM approaches will negatively affect perceptions of CDR approaches, forestalling their serious consideration (Colvin et al. 2019; Horton 2015). Given the substantial differences within CDR and SRM categories, Colvin et al. (2019) argue individual technologies should be considered independently to facilitate nuanced discussion and avoid sweeping generalisations. Other framing issues are the need to evaluate climate engineering approaches within the broader context of alternative strategies such as mitigation and adaptation (Bellamy et al. 2012; Bellamy and Lezaun 2017), to ensure that linguistic frames avoid use of natural analogies, such as likening air capture to 'artificial trees' (Corner and Pidgeon 2015), and to recognise that terms such as 'insufficient mitigation' or 'climate emergency' narrow and pre-empt the direction of discussions (Bellamy et al. 2013; Bellamy and Lezaun 2017; Corner et al. 2011).

Since there is concern among social scientists that framing may have undue effects on perspectives of climate engineering, we take care to minimise such effects. We avoid the term climate engineering and instead refer to potential solutions to rising global temperatures. We avoid the use of natural analogies (Corner and Pidgeon 2015) and statements about a 'climate emergency' or 'insufficient mitigation' (Bellamy et al. 2013; Corner et al. 2011). We define responses as distinct policy options alongside adaptation and mitigation, present the approaches individually, and apply new scientific knowledge to update the descriptions and images used.

\section{Methods}

The research method is validated in two ways. First, its theoretical foundations are well established in cognitive psychology. Second, the brand imaging techniques developed from these theories by branding experts are widely applied commercially. The method's founding theories of Associative Network Theory of Memory (ANTM) and the Adaptive Control of Thought model (Anderson 1983; Anderson and Bower 1974) describe how a concept is encoded, retrieved and stored in memory. When humans are faced with an external stimulus such as an image or concept description, information stored in memory actively cascades through a network of associated nodes to help with interpretation and problem solving (Wright et al. 2014). Brand experts developed these theories to 
systematically and quantitatively elicit cognitive associations with concepts or brands that are mapped in images (Romaniuk 2013; Wright et al. 2014). The 2012 study demonstrated that this system adapts to other domains such as emerging science by measuring the attributes associated with climate engineering proposals and is replicated in this study.

The surveys undertaken in 2012 commenced with qualitative research on climate engineering associations $(n=30)$ followed by quantitative data collection $(n=2028)$ on the public perceptions of three CDR approaches Biochar, Air Capture, Enhanced Weathering, and three SRM approaches Cloud Brightening, Stratospheric Aerosols and Mirrors in Space (Wright et al. 2014). The 2018 surveys undertook new qualitative research $(\mathrm{n}=15)$ followed by new quantitative data collection $(\mathrm{n}=$ 2989) for Bioenergy with Carbon Capture and Storage (BECCS), Direct Air Capture and Carbon Storage $(D A C C S)$, Enhanced Weathering $(E W)$, Marine Cloud Brightening $(M C B)$, Stratospheric Aerosol Injection $(S A I)$ and Mirrors in Space $(M I S)$. Since the choice of climate engineering approaches can affect research outcomes (Bellamy et al. 2012), we acknowledge the current study excludes other possible climate engineering approaches (e.g. biochar, cirrus cloud thinning, and afforestation) and outline the rationale behind our choices. Public perceptions of BECCS remain understudied (Bellamy et al. 2019) despite playing a major role in several modelling scenarios to meet $1.5^{\circ} \mathrm{C}$ or $2^{\circ} \mathrm{C}$ targets, in the IPCC (2014) Fifth Assessment Report. Therefore, BECCS replaces Biochar for evaluation to maintain a balance of three CDR and three SRM approaches. Replacing MIS was also considered due to issues of feasibility. However, public and policy interest in MIS has continued to be expressed, for example with American democratic candidate Andrew Yang campaigning on providing $\$ 800$ million USD in funding for SRM research, including MIS. Thus, MIS is retained in the current study. Table 1 briefly summarises the CDR and SRM approaches from the 2012 and 2018 surveys.

Table 1 about here. 
To reflect recent advances in scientific knowledge we update the descriptions of each climate engineering approach used in the 2012 materials and draw on recent imagery used by the Royal Society and Royal Academy of Engineering (2018) and Lawrence et al. (2018). The concept boards use consistent formatting and content across techniques. Descriptions begin with three sentences describing the concept, method of application and advantages, including the cooling effect and other benefits. Next, two or three sentences outline the costs, possible unintended outcomes and any caveats associated with implementation. The final two or three sentences outline how the method would be implemented over time, the scale of implementation required, and indicate whether the method would require international agreements. Final descriptions are between 93-100 words and avoid use of adjectives from the attribute list. Some similar or identical phrases are used in multiple approaches where appropriate. Imagery is designed following similar matching criteria for scale, content and colour. As in the original study, we do not attempt to evaluate visual processing of imagery. The concept boards and questionnaires were peer-reviewed within the authorship team with additional feedback solicited from two independent international experts and from citizens within the sampling frame. Minor word adjustments were applied after this feedback and the concepts boards were further validated through successful application in the qualitative interviews $(n=15)$. Figure 1 provides an example of the BECCS concept imagery and description, used in the qualitative and quantitative materials (see Supplementary Figure 1 for all six concept boards).

Figure 1 about here.

\subsection{Qualitative Phase (2018)}

The aim of the qualitative phase is to explore the ways that citizens think about the topic to identify any new constructs associated with climate engineering approaches compared to the 2012 research (Wright et al. 2014). The output of this phase is a set of common attributes that are used in the quantitative phase as criteria for evaluating climate engineering approaches. Using attributes (criteria) developed by citizens incorporates diverse and inclusive public perspectives to 'open up' the 
quantitative appraisal process (Bellamy et al. 2016). Whereas criteria generated by experts or researchers may not accurately reflect public perspectives and could bias appraisal outputs.

The qualitative phase includes fifteen in-depth interviews using the Kelly's Repertory Grid elicitation technique and follows the method previously applied in the qualitative phase of the 2012 study (Rogers and Ryals 2007; Wright et al. 2014). The sample is purposively selected to maximise demographic diversity and consists of 53\% female and 47\% male New Zealanders, aged between 21 and 63 years, and with varied occupations (Supplementary Table 1). The Kelly's Repertory Grid technique invites participants to identify two concepts out of a set of three, and to explain how the pair are alike yet different from the third. The method in this case is used to identify a list of attributes associated with each climate engineering approach. Prior to the exercise, participants read all six concept boards. Participants were then sequentially presented with six sets of three concept boards to evaluate similarities and differences. Sets were predetermined to ensure each concept was evaluated three times. The presentation order of the six sets and the order of three concept boards within each set was randomised by the interviewer. Responses were audio-recorded and analysed by themes to identify, group, and total attributes commonly elicited from participants. The attributes emerging from the qualitative phase in 2018 were congruent with those uncovered in the 2012 study. We therefore proceeded to the quantitative phase using the same 12 attributes as the earlier study (Wright et al. 2014).

\subsection{Quantitative Phase (2018)}

\subsubsection{Sampling}

The quantitative phase consists of large-scale surveys in the United Kingdom (number of participants, $n=751)$, United States $(n=746)$, Australia $(n=763)$, and New Zealand $(n=729)$, using a commercial online panel provider; Dynata (formerly ResearchNow, https://www.dynata.com). Survey invitations are topic-blind to mitigate response bias. Invitations are issued to panel members continuously until sample and demographic quotas are met. Recruitment bias is unlikely given the substantial size of the panels ( $n=1,200,000$ in the United Kingdom, $n=11,570,000$ in United States, $n=$ 780,000 in Australia, and $n=260,000$ in New Zealand). Coverage bias is also minimised with high 
levels of internet access in all four countries ${ }^{1}$. The surveys were conducted in early December (week commencing 30 November) 2018, the same time of year as the 2012 study (Wright et al. 2014).

\subsubsection{Participants}

Supplementary Tables 2, 3, 4 and 5 report the demographic breakdown of the quantitative samples along with comparative census data or similar independent population estimates for gender, age and political support. The sample characteristics for each country show a satisfactory spread of demographics with overall only small deviations from population estimates. Therefore, sample composition is acceptable for the purposes of this research.

\subsubsection{Data collection}

The survey questionnaire is the same for all countries except for minor differences in demographic items. The questionnaire was pretested among several survey design experts and non-experts who experienced no major difficulties in interpreting questions, understanding the concepts or the survey flow. Minor improvements were made to the survey design after this feedback. Prior to the survey's full launch, responses from 70 initial participants were checked to ensure the questions were not misunderstood. No further changes were made, and the full launch proceeded until quotas were achieved.

The questionnaire prepares participants to give meaningful responses by briefly introducing the topic and asking general questions about global warming (see Supplementary Figure 1 for questionnaire wording). Respondents then move to the concept evaluation block where they are sequentially presented with concept boards for each climate engineering approach. Respondents evaluate all six climate engineering approaches individually by selecting from the pre-determined list of 12 attributes confirmed in the qualitative phase of research. The presentation order of concepts and attributes is randomised to avoid order effects. Additional questionnaire items are included to

\footnotetext{
${ }^{1}$ Internet access across the four samples is as follows: $90 \%$ in the United Kingdom (Office for National Statistics 2018), 84\% in the United States (Ryan and Lewis 2017), 86\% in Australia (Australia Bureau of Statistics 2017), and 94\% in New Zealand (Díaz Andrade et al. 2018).
} 
supplement the principal analysis of respondents' attribute associations, including support for small scale trials, understanding of concept boards, ecological views, and prior knowledge of the climate engineering approaches (see Supplementary Tables 6 and 7 for question wording). The survey concludes with demographic items.

\subsubsection{Measures}

\section{Attribute associations}

Public perceptions are measured from the count of attribute associations elicited from individual participants for each climate engineering approach. Responses are measured using a free choice, pickany format and each attribute is coded as ' $1=$ selected' or ' $0=$ not selected' for each approach (see Supplementary Table 6 for question wording). Modelling mental associations using a binary variable is a requirement of the current method and is appropriate as an association can either exist or not exist in memory (Romaniuk 2013). Measuring attribute associations in this manner also has significant advantages over traditional attitudinal scales that are prone to 'non-attitude' responses. Rather than measuring fabricated non-attitudes, the current method relies on pre-existing memory associations. Where a respondent has no attitudes toward a climate engineering approach, the attribute selection task would yield few attribute associations compared to respondents with strong attitudes. In contrast, attitudinal scales fail to differentiate between non-attitudes and genuine responses and give each response equal weight in subsequent analysis. Consequently, attribute association measures are comparatively less prone to bias from non-attitude responding.

Following diagnostic tests (Supplementary Table 8) the final list of attributes is reduced to 10 to avoid duplicate measurement from overlapping attributes (Romaniuk 2013). The final attribute list maintains a balance of five positive and five negative attributes. To enable further analysis a net positive variable is calculated as the sum of each respondents' positive attribute associations minus the sum of their negative attribute associations for each approach. The principal analysis involves aggregating the net positive variable by individual technique, by CDR techniques, by SRM techniques, or over all six climate engineering techniques to make each relevant comparison. To 
enable comparisons between samples of different sizes, the net positive value is converted into a percentage where appropriate.

The statistical properties of the net positive variable are examined using aggregation by respondent. The overall net positive variable can take any value between -30 and 30 where ' 0 ' represents net-zero positive associations (mean ranging from -3.28 to -4.86 across all countries, standard deviation ranging from 6.43 to 7.19 ). Graphical analysis shows a close approximation to the normal distribution in all four countries (Supplementary Figure 3 and 4) and kurtosis and skewness are also acceptable (Supplementary Table 9) indicating the net positive variable is suitable for further analysis using standard statistical methods.

Univariate tests of associations between the net positive variable and demographic variables identify statistically significant relationships with Age and Political Party variables (see section 3.3.1 and Supplementary Table 10). However, multivariate analysis does not reveal any significant effect of demographics on the net positive variable once 2-way interactions and Bonferroni corrections are considered (Supplementary Table 11). Therefore, neither Age nor Political Party are deemed necessary as covariates for the principal analyses.

\section{Understanding}

To check the adequacy of the concept boards, respondents are asked whether they could explain each approach to someone else using a five-point Likert-style scale (see Supplementary Table 6 for question wording) where $1=$ Strongly agree and $5=$ Strongly disagree (mean ranges from 2.68 to 2.88 across technologies, standard deviation ranges from 0.99 to 1.03$)$. Results show similar satisfactory levels of understanding to the 2012 study: $34-48 \%$ indicating they could explain the concept to someone else, $32-41 \%$ are neutral, and only $16-27 \%$ disagree.

\section{Support for small-scale trials}

For each technique, participants are asked to indicate their support for small scale trials on a five-point Likert-style scale (see Supplementary Table 6 for question wording) where $1=$ Strongly agree and $5=$ Strongly disagree (mean ranges from 2.71 to 3.25 across technologies, standard deviation ranges from 
1.05 to 1.10$)$. The subject of small-scale trials reflects the current state of climate engineering $R \& D$ where computer modelling research is already underway and the potential progression to outdoor trials will likely become a matter of public concern.

\section{Prior awareness}

Following the concept evaluations, respondents are asked "Did you know about any of these proposals before you began this survey?'. Responses are coded as ' $0=$ no' or ' $1=$ yes' (mean ranges from 0.14 to 0.18 across countries, standard deviation ranges from 0.34 to 0.38 ).

\section{Ecological views}

Ecological views are measured using five items from the New Ecological Paradigm (NEP) scale (Dunlap et al. 2000). Prior public perception studies yield either mixed or non-significant relationships between NEP items and support for different climate engineering technologies (Braun et al. 2018a; Braun et al. 2018b; Dütschke et al. 2016; Merk and Pönitzsch 2017; Merk et al. 2015). Responses are recorded using a five-point Likert-style scale where $1=$ Strongly agree and $5=$ Strongly disagree. Three items are worded so that agreement indicates a strong ecological orientation, whereas agreement with the other two items indicate a weak ecological orientation (see Supplementary Table 7 for question wording). All items are recoded for analysis so that $1=$ strong ecological orientation and $5=$ weak ecological orientation .

Factor analysis using principal component analysis with varimax rotation identifies three positively worded items that load heavily on one factor accounting for $37.5-40.2 \%$ of the total variation, whereas the negatively worded items load on a separate factor. The scale is therefore reduced to the three positively worded items (Cronbach's $\alpha$ ranging from 0.679 to 0.727 across countries, average 0.715 ) and aggregated to form an overall NEP score where 15 represents a weak ecological orientation and 3 represents a strong ecological orientation (mean ranging from 5.73 to 6.56 across countries; standard deviation ranging from 2.14 to 2.53 ). The distribution of this variable is approximately normal in all four countries (skewness ranging from 0.69 to 0.87 across countries; kurtosis ranging from 0.37 to 1.27 ), so bivariate correlations are used to assess the relationship between the NEP variable and net positive association variables. 


\subsubsection{Comparisons between Samples}

Differences between countries in the CDR and SRM net positive variables are assessed using ANOVA (Supplementary Table 12). A Levene test indicates heterogeneous variance between samples, although the ratios of variance between samples are less than 1.5, indicating the ANOVA is still appropriate. We also test for shifts in public perceptions over time by comparing AU and NZ samples from the current 2018 study against those collected in 2012 by Wright et al. (2014). Due to the replacement of Biochar with BECCS, we test for differences in the net positive variables for DACCS, $E W, M C B, M I S$ and $S A I$ using independent sample $t$-tests.

\subsubsection{Construction of Concept Maps}

To explore the nuanced differences in public perceptions between climate engineering approaches, a concept map for each approach is developed through a chi-square calculation of expected cell counts for each attribute (see Supplementary Table 13), calculation of percentage skews (deviations) between actual counts and expected values (see Supplementary Table 14), and then reporting of skews in graphical format (see Supplementary Figures 5-8 for concepts maps of all approaches for each country). To further explore the rationale behind the perceived differences between approaches the absolute values of attribute skews are averaged across the six approaches to produce the mean skew per attribute (see Supplementary Table 14).

\section{Results}

\subsection{Public Awareness}

Despite strong arguments for early public deliberation and increasing availability of information, the public continue to demonstrate little knowledge of climate engineering approaches (Cummings et al. 2017; Wright et al. 2014). In 2012, respondents in AU and NZ surveys were asked whether they had prior knowledge of climate engineering approaches. Only $18 \%$ of the AU and NZ respondents acknowledged some awareness of these techniques (Wright et al. 2014). In the 2018 survey the same question found only $18 \%(\mathrm{UK}), 16 \%(\mathrm{USA}), 14 \%(\mathrm{AU})$ and $15 \%(\mathrm{NZ})$ of respondents reported prior 
knowledge of the climate engineering approaches tested (95\% confidence intervals are plus or minus 1.2 to 1.4 percentage points).

\subsection{Attribute Popularity}

Attribute popularity (salience) is measured as each attribute's share of all associations for that country. Although there are substantial variations in share of associations between attributes, there are negligible differences in shares of associations between countries or between years (Table 2). The shares of associations show remarkable consistency with correlations of no less than $r=0.99$ between countries (within each year) and $r=0.98$ between years (within AU and NZ).

\section{Table 2 about here.}

Of the ten attributes analysed. The most frequently chosen by respondents are the three negative attributes unknown effects, risky, and artificial. In AU and NZ these three attributes demonstrate little change from 2012 and still account for just over $50 \%$ of all associations. When the same data are aggregated by climate engineering approaches they yield a count of associations for each approach, together with the 'net positive' expressed as the total associations for that approach. This calculation of a 'net positive' variable enables the public perceptions of the six approaches to be ranked on that variable (Table 3).

Table 3 about here.

BECCS replaces Biochar as the least negatively perceived approach, whereas Stratospheric Aerosol Injection, overtakes Mirrors in Space as the most negatively perceived approach. Remarkably, net positive associations for all six approaches show little variation between countries and only minor 
changes over time. They remain broadly negative, although CDR approaches continue to be perceived less negatively than SRM approaches.

\subsection{Variables Influencing Public Perceptions}

\subsubsection{Demographics}

Demographic effects on the net positive variable were examined both individually, through univariate tests (Supplementary Table 10), and jointly through multivariate tests that included 2-way interactions (Supplementary Table 11) to investigate whether demographic characteristics influence individuals' evaluations of climate engineering. Univariate tests reveal statistically significant relationships between the net positive variable and Age and Political Party variables. Age is recorded as year-born and coded in reverse to give the intuitive interpretation of increasing numbers being equivalent to increasing age, indicating older people tend to be more negative about climate engineering than younger people; however, the effect is small as indicated by r-values of less than 0.30 . Turning to consider political party affiliation, Republicans in the US are more negative towards climate engineering than Democrats. A significant relationship is also found for in Australia, UK and NZ where respondents who selected 'Other (Please Specify):' were more negative about climate engineering; however, several of these respondents did not provide a clear affiliation (e.g. "none", "I don't know", "prefer not to say"). As noted earlier, multivariate analysis does not reveal any significant effect of demographics on the net positive variable once 2-way interactions and Bonferroni corrections are considered.

\subsubsection{Ecological Views}

For CDR proposals, strong ecological views are significantly correlated with less negative net associations in UK $r=0.142, p<.001)$, US $r=0.168,(p<.001)$, and NZ $r=0.117,(p=.002)$. In contrast, for SRM proposals, pro-ecological views are significantly correlated with more negative net associations in UK $r=-0.103,(p=.005)$ and AU $r=-0.095,(p=.009)$. These results suggest ecological views influence public perceptions of climate engineering and support the proposition that the interaction between ecological and technological views are nuanced and not diametrically opposed (Scarrow 2019). Increasing pro-ecological views among the public may further increase support for 
CDR and reduce support for SRM. However, caution is needed when interpreting these findings as ecological attitudes are known to be poor predictors of actual behaviour (Wright and Klÿn 1998).

\subsection{Differences between Samples}

We test for differences in perceptions of CDR and SRM proposals between countries with ANOVA and a Games Howell post hoc test (Supplementary Table 12). The analysis reveals the UK sample is slightly less negative towards CDR approaches than the US, AU, and NZ samples $\left(F_{3,2985}=3.659, p=\right.$ .012). Similarly, the UK and US samples were both slightly less negative towards SRM approaches than the AU and NZ samples $\left(F_{3,2985}=13.464, p<.001\right)$. Although these differences are significant, they are not substantial (see Figure 2).

Considering other changes from the 2012 data, in 2018 NZ public perceptions are somewhat less negative towards $E W(t=-2.973, p=.003), M C B(t=-5.615, p<.001), S A I(t=-4.202, p<.001)$ and MIS $(t=-6.685, p<.001)$, and AU public perceptions showed no significant differences between years based on a Bonferroni-corrected critical $p$ value of .01. The net positive associations for climate engineering approaches show remarkable consistency, with correlations ranging from $r=0.96$ to $r=$ 0.99 between countries (within each year), and $r=.98$ between years (for AU and NZ).

Figure 2 provides a graphical representation of the 2012 and 2018 data. Although all four countries are economically developed anglophone democracies, they retain substantial geographic, cultural, political and economic differences, and so the similarity in public perceptions is striking.

\section{Figure 2 about here.}

Fig. 2 Net positive memory associations for climate engineering approaches. The bar chart shows that public perceptions of climate engineering proposals are negative, although less so for CDR than SRM. For each proposal there is little variation between countries and over time. Error bars show 95\% Confidence Intervals. 


\subsection{Concept Maps}

Concept maps for each climate engineering approach present the percentage skews (deviations) between actual counts and expected values, for each attribute, in a graphical format. Positive skews show the attribute is strongly associated with the approach. Negative skews show the attribute is weakly associated with the approach. As found in 2012 (Wright et al. 2014) the concept maps vary considerably between approaches yet are similar between countries (see Figure 3 for UK concept map and Supplementary Figures 5-8 for other countries).

\section{Figure 3 about here.}

Fig. 3 Concept maps for climate engineering approaches in the UK show percentage point deviations from expected attribute counts. CDR approaches skew toward more positive attributes (top row panels), whereas SRM approaches skew toward more negative attributes (bottom row panels).

The concept maps present attributes in inverse order of popularity with positive attributes at the top. CDR approaches skew towards the positive attributes (top row panels) whereas SRM approaches skew towards the negative attributes (bottom row panels). The sources of the overall skew can be understood by examining skew for the individual attributes (see supplementary table 14 for the UK example). The attributes contributing most towards negative skews are unknown effects, risky and artificial. The attributes contributing most to positive skews are environmentally friendly, controllable and long-term sustainability. Overall, these results show that public perceptions of climate engineering approaches continue to be negative, are very similar between the countries examined, and that CDR approaches continue to be perceived substantially less negatively than SRM approaches. Commercial branding theory indicates that substitutable brands competing within a product category tend to have highly similar rankings of attribute associations; as CDR and SRM have highly dissimilar rankings they may be perceived as different categories, or as non-substitutable activities as far as these respondents are concerned (Romaniuk 2013). Branding theory also posits that brands with 
distinctive images receive more attention than brands with indistinct images (Romaniuk 2013); we therefore conclude that $B E C C S$ and $D A C C S$ with distinctively and positively skewed concept maps are likely to receive the most positive public reaction, $S A I$ and $M I S$ with distinctively and negatively skewed concept maps are likely to receive the most negative public reaction, whereas $E W$ and $M C B$ with more indistinct and minor skews in their concept maps are likely to generate more subdued public reactions.

\subsection{Support for Trials}

Beyond perceptions of climate engineering, we also assess support for further small-scale trials for each approach. Support is measured using a five-point scale with $1=$ Strongly Agree and $5=$ Strongly Disagree and is combined across countries. Responses are aggregated into agree, neutral and disagree categories for reporting (Table 4). The results show mixed support for small-scale trials of individual approaches with slightly higher support for CDR trials than SRM. The final column demonstrates that the variation in average agreement for small scale trials closely follows the variation in average net positive associations for each approach.

\section{Table 4 about here.}

\section{Discussion}

Despite careful consideration of concerns about climate engineering frames and revising the content of the concept presentations to reflect new scientific knowledge, the net positive associations for the five climate engineering approaches of $D A C C S, E W, M C B, S A I$ and $M I S$ are remarkably similar between countries in 2018 as well as between years for AU and NZ. The consistency of these results provides strong evidence that our quantitative approach to measuring public perceptions is robust. The similarities between the 2012 and 2018 measurements also indicate that where framing effects or nonattitude responding may have impacted on public evaluations, the magnitude of impact is unlikely to substantially shift overall evaluations. Nonetheless, it is important that future work continues to track public opinion as more information emerges in the public sphere and awareness of climate 
engineering becomes widespread. Continued inquiry using experimental designs is also needed to explore antecedents to public opinion on climate engineering and estimate how public perceptions will develop over time.

Several researchers have raised concern that broadly categorising heterogeneous CDR and SRM technologies under the banner of climate engineering is ineffective for informing policy discussions (Minx et al. 2018) and that higher risk perceptions of SRM technologies may undermine the pursuit of CDR technologies (Colvin et al. 2019). Although perceptions of all six climate engineering techniques are predominantly negative, the substantial difference in perceptions between CDR and SRM techniques suggest that citizens do indeed perceive the two groups of technologies as conceptually distinct categories. As in the original 2012 study, we conclude that SRM technologies continue to yield comparatively negative perceptual evaluations and are more likely to elicit more negative public reactions than CDR technologies (Wright et al. 2014). The perceived polarisation provides further justification to separate CDR and SRM as distinct classes of action for addressing climate change.

Another viewpoint argues that it is important to facilitate a nuanced discussion on individual technologies to avoid broad generalisations across heterogeneous technologies (Colvin et al. 2019). Considering the concept maps of six individual technologies (see Figure 3 for UK concept map and Supplementary Figures 5-8 for other countries) there are clear differences in public perceptions between individual technologies within the CDR and SRM categories. The consistency of these differences across samples demonstrate that public perceptions of climate engineering are technology specific and nuanced. A prime example is the difference in perceptions between $M C B$ and $S A I$. Though both technologies fall under the category of SRM, $M C B$ elicits substantially fewer negative associations than $S A I$ with a difference in net positive associations of between $10-23$ percentage points across the four 2018 samples (see Table 3). There is a risk that painting perceptions of SRM (or CDR) as broadly negative overlooks nuanced differences between individual technologies and could hinder their future development. These findings further evidence the importance of differentiating between climate engineering technologies at the individual level (Colvin et al. 2019). 
Though technical understanding of climate engineering technologies has advanced, media coverage has increased (Doyle 2017; Watts 2018), and methods of public engagement are continually refined, it is clear from consistently low public awareness that current attempts at public engagement are insufficient to facilitate global discourse. A potential reason for this is the concerted effort of social scientists to move away from deficit model of science communication toward consultative and participative mechanisms of public engagement. Indeed, the deficit model is widely discredited on the grounds that public communication mechanisms are ineffective at shifting public perceptions (Corner and Pidgeon 2010). However, coordinated public communication mechanisms need not be considered a retreat toward deficit ideals if the messages are aimed at communicating objective information to increase public awareness, rather than aiming to influence public perceptions. Commercial branding theory suggests consumers rarely consider brands they are unfamiliar with (Sharp 2010) likewise, citizens are unlikely to deliberate on emerging scientific concepts they are unaware of. If a large portion of the population are excluded from climate engineering discourses due to low awareness, then the current process of public engagement can hardly be considered democratic. Increasing information on climate engineering in the public sphere would facilitate broader public discourse on the matter outside the context of structured engagement activities. By this reasoning, communicative mechanisms of public engagement still offer some value as a tool for building public awareness.

As the growing necessity for solutions to climate change continues to drive research and development of climate engineering technologies, public engagement efforts need to expand rapidly across global publics. Consultative mechanisms of public engagement, such as the current study, provide excellent tools for eliciting and comparing diverse perspectives at a global scale as well as tracking shifts in public perceptions over time. Likewise, the growth of information communication technologies also presents opportunities to administer web-based or virtual participative mechanisms across global audiences. Regardless of the mechanism, it is important that public engagement occurs sufficiently early to allow public perceptions and concerns to influence the development of climate engineering technologies prior to significant technological development and lock-in. 
Since 2012, climate engineering approaches have received increasing attention in international forums. There is more information available in the public domain and the mainstream print media and increased and regular discussion in the context of the Paris Climate Agreement targets. Yet our results show that public knowledge of climate engineering approaches remains low with only small differences in public perceptions between countries and over time. Factors, including age, political affiliation and pro-ecological views, yield mixed associations with climate engineering perceptions. However, further studies are needed to observe whether these factors remain significant as climate engineering discourse develops.

Perceptions of climate engineering are increasingly relevant following the cancellation of the SPICE experiment and as momentum builds behind the SCoPEx project. Perceptions of SAI are overwhelmingly negative and less than a quarter of respondents support small-scale trials. Though the aerosol particles released through SCoPEx are relatively benign and inconsequential, there is a risk of backlash from an uninformed public toward what might be perceived as initial attempts at SAI deployment.

Even with growing warnings of the need for urgency in climate responses, and greater knowledge of potential large-scale impacts of climate change, our fresh measurement of public engagement with climate engineering approaches show that perceptions are largely unchanged from 2012. Concerns that public discussion of climate engineering could reduce pressure to cut emissions have not been realised, as there are no substantive changes to public knowledge in this area. The climate science community and policymakers can still structure public debate on these novel scientific concepts. The increasingly urgent question is how best to use this opportunity for initial engagement with the public, given the extreme challenges presented by anthropogenic induced global warming and the associated threats to environmentally sustainable futures as partially addressed by the Paris Agreement targets. 


\section{References}

Anderson JR (1983) A spreading activation theory of memory J Verb Learn Verb Be 22:261-295 https://doi.org/10.1016/S0022-5371(83)90201-3

Anderson JR, Bower GH (1974) Human associative memory. John Wiley \& Sons, Washington, DC

Asher H (2017) The problem of nonattitudes. In: Polling and the public: What every citizen should know. 9th edn. Sage, Thousand Oaks, CA, pp 43-72

Australia Bureau of Statistics (2017) 8146.0 - Household use of information technology, Australia, 2016-17. http://www.abs.gov.au/ausstats/abs@.nsf/mf/8146.0. Accessed February 27, 2019

Bawden T (2016) COP21: Paris deal far too weak to prevent devastating climate change, academics warn. https://www.independent.co.uk/environment/climate-change/cop21-paris-deal-far-tooweak-to-prevent-devastating-climate-change-academics-warn-a6803096.html.

Bellamy R, Chilvers J, Vaughan NE (2016) Deliberative mapping of options for tackling climate change: Citizens and specialists 'open up' appraisal of geoengineering Public Underst Sci 25:269-286 https://doi.org/10.1177/0963662514548628

Bellamy R, Chilvers J, Vaughan NE, Lenton TM (2012) A review of climate geoengineering appraisals Wiley Interdiscip Rev Clim Chang 3:597-615 https://doi.org/10.1002/wcc.197

Bellamy R, Chilvers J, Vaughan NE, Lenton TM (2013) 'Opening up' geoengineering appraisal: Multi-criteria mapping of options for tackling climate change Glob Environ Chang 23:926937 https://doi.org/10.1016/j.gloenvcha.2013.07.011

Bellamy R, Healey P (2018) ‘Slippery slope’ or 'uphill struggle'? Broadening out expert scenarios of climate engineering research and development Environ Sci Pol 83:1-10 https://doi.org/10.1016/j.envsci.2018.01.021

Bellamy R, Lezaun J (2017) Crafting a public for geoengineering Public Underst Sci 26:402-417 https://doi.org/10.1177/0963662515600965

Bellamy R, Lezaun J, Palmer J (2019) Perceptions of bioenergy with carbon capture and storage in different policy scenarios Nat Commun 10:743 https://doi.org/10.1038/s41467-019-08592-5 
Biermann F, Möller I (2019) Rich man's solution? Climate engineering discourses and the marginalization of the Global South Int Environ Agreem-P 19:151-167 https://doi.org/10.1007/s10784-019-09431-0

Braun C, Merk C, Pönitzsch G, Rehdanz K, Schmidt U (2018a) Public perception of climate engineering and carbon capture and storage in Germany: survey evidence Clim Policy 18:471-484 https://doi.org/10.1080/14693062.2017.1304888

Braun C, Rehdanz K, Schmidt U (2018b) Exploring public perception of environmental technology over time J Environ Plann Man 61:143-160 https://doi.org/10.1080/09640568.2017.1291414

Burns E, Flegal JA, Keith DW, Mahajan A, Tingley D, Wagner G (2016) What do people think when they think about solar geoengineering? A review of empirical social science literature, and prospects for future research Earth's Future 4:536-542 https://doi.org/10.1002/2016EF000461

Chilvers J (2009) Deliberative and participatory approaches in environmental geography. In: Noel Castree DD, Diana Liverman, Bruce Rhoads (ed) A Companion to Environmental Geography. John Wiley \& Sons Ltd, West Sussex, UK,

Colvin RM et al. (2019) Learning from the climate change debate to avoid polarisation on negative emissions Environ Commun https://doi.org/10.1080/17524032.2019.1630463

Corner A, Parkhill KA, Pidgeon NF (2011) 'Experiment Earth?' Reflections on a public dialogue on geoengineering: Reflections on a public dialogue on geoengineering

Corner A, Pidgeon NF (2010) Geoengineering the climate: The social and ethical implications Environment 52:24-37 https://doi.org/10.1080/00139150903479563

Corner A, Pidgeon NF (2015) Like artificial trees? The effect of framing by natural analogy on public perceptions of geoengineering Climatic Change 130:425-438 https://doi.org/10.1007/s10584014-1148-6

Corner A, Pidgeon NF, Parkhill KA (2012) Perceptions of geoengineering: Public attitudes, stakeholder perspectives, and the challenge of 'upstream' engagement Wiley Interdiscip Rev Clim Chang 3:451-466 https://doi.org/10.1002/wcc.176

Cummings CL, Lin SH, Trump BD (2017) Public perceptions of climate geoengineering: a systematic review of the literature Clim Res 73:247-264 https://doi.org/10.3354/cr01475 
Díaz Andrade A, Hedges MR, Karimikia H, Techatassanasoontorn A (2018) World Internet Project: The Internet in New Zealand 2017. New Zealand Work Research Institute, Auckland Doyle A (2017) Climate scientists sucking carbon dioxide from air and dimming sun's rays with chemicals to cool planet. https://www.independent.co.uk/environment/geo-engineeringtechnology-climate-change-environment-climeworks-carbon-dioxide-chemicals-dimminga7860356.html.

Dunlap RE, Van Liere KD, Mertig AG, Jones RE (2000) New trends in measuring environmental attitudes: measuring endorsement of the new ecological paradigm: a revised NEP scale J Soc Issues 56:425-442 https://doi.org/10.1111/0022-4537.00176

Dütschke E, Wohlfarth K, Höller S, Viebahn P, Schumann D, Pietzner K (2016) Differences in the public perception of CCS in Germany depending on $\mathrm{CO} 2$ source, transport option and storage location Int J Greenh Gas Con 53:149-159 https://doi.org/10.1016/j.ijggc.2016.07.043

Fiorino DJ (1990) Citizen participation and environmental risk: A survey of institutional mechanisms Sci Technol Hum Values 15:226-243 https://doi.org/10.1177/016224399001500204

Heyward C (2013) Situating and abandoning geoengineering: a typology of five responses to dangerous climate change Polit Sci Polit 46:23-27 https://doi.org/10.1017/S1049096512001436

Horton JB (2015) Why we should treat SRM and CDR separately. https://ceassessment.org/why-weshould-treat-srm-and-cdr-separately-joshua-b-horton/.

IPCC (2014) Climate Change 2014: Synthesis Report. Contribution of Working Groups I, II and III to the Fifth Assessment Report of the Intergovernmental Panel on Climate Change. R.K. Pachauri and L.A. Meyer (eds), IPCC, Geneva, Switzerland

Irvine P, Emanuel K, He J, Horowitz LW, Vecchi G, Keith D (2019) Halving warming with idealized solar geoengineering moderates key climate hazards Nat Clim Chang 9:295-299 https://doi.org/10.1038/s41558-019-0398-8

Ki-moon B (2019) Governing Geoengineering. https://www.projectsyndicate.org/commentary/climate-change-geoengineering-technologies-governance-by-banki-moon-2019-03. 
Kravitz B et al. (2019) Holistic assessment of SO2 injections using CESM1 (WACCM): Introduction to the special issue J Geophys Res-Atmos 124:444-450 https://doi.org/10.1029/2018JD029293

Kravitz B et al. (2018) The Geoengineering Model Intercomparison Project-introduction to the second special issue Atmos Chem Phys https://doi.org/10.5194/acp-special_issue376-preface Lawrence MG et al. (2018) Evaluating climate geoengineering proposals in the context of the Paris Agreement temperature goals Nat Commun 9:3734 https://doi.org/10.1038/s41467-018$05938-3$

Lomax G, Workman M, Lenton T, Shah N (2015) Reframing the policy approach to greenhouse gas removal technologies Energy Policy 78:125-136 https://doi.org/10.1016/j.enpol.2014.10.002

MacMartin DG, Ricke KL, Keith DW (2018) Solar geoengineering as part of an overall strategy for meeting the 1.5 C Paris target Phil Trans A Math Phys Eng Sci 376 https://doi.org/10.1098/rsta.2016.0454

Merk C, Pönitzsch G (2017) The role of affect in attitude formation toward new technologies: The case of stratospheric aerosol injection Risk Anal 37:2289-2304 https://doi.org/10.1111/risa.12780

Merk C, Pönitzsch G, Kniebes C, Rehdanz K, Schmidt U (2015) Exploring public perceptions of stratospheric sulfate injection Climatic Change 130:299-312 https://doi.org/10.1007/s10584$014-1317-7$

Minx JC et al. (2018) Negative emissions - Part 1: Research landscape and synthesis Environ Res Lett 13 https://doi.org/10.1088/1748-9326/aabf9b

National Academies of Science (2015a) Climate intervention: carbon dioxide removal and reliable sequestration. National Academies Press, Washington, DC

National Academies of Science (2015b) Climate Intervention: reflecting sunlight to cool Earth. National Academy Press, Washington, DC

Office for National Statistics (2018) Internet access - households and individuals, Great Britain: 2018. https://www.ons.gov.uk/peoplepopulationandcommunity/householdcharacteristics/homeintern 
etandsocialmediausage/bulletins/internetaccesshouseholdsandindividuals/2018. Accessed 27 February 2019

Rayner S, Heyward C, Kruger T, Pidgeon NF, Redgwell C, Savulescu J (2013) The Oxford Principles Climatic Change 121:499-512 https://doi.org/10.1007/s10584-012-0675-2

Rogers-Hayden T, Pidgeon NF (2007) Moving engagement “upstream"? Nanotechnologies and the Royal Society and Royal Academy of Engineering's inquiry Public Underst Sci 16:345-364 https://doi.org/10.1177/0963662506076141

Rogers B, Ryals L (2007) Using the repertory grid to access the underlying realities in key account relationships Int J Market Res 49:595-612 https://doi.org/10.1177/147078530704900506

Romaniuk J (2013) Modeling mental market share J Bus Res 66:188-195 https://doi.org/10.1016/j.jbusres.2012.07.012

Rowe G, Frewer LJ (2005) A typology of public engagement mechanisms 30:251-290 https://doi.org/10.1177/0162243904271724

Royal Society, Royal Academy of Engineering (2018) Greenhouse gas removal.

Ryan C, Lewis JM (2017) Computer and internet use in the United States: 2015. U.S. Census Bureau, Washington, DC

Salter S, Stevenson T, Tsiamis A (2014) Engineering ideas for brighter clouds. In: Hester RE, Harrison RM (eds) Geoengineering of the climate system., vol 38. Issues in Environmental Science and Technology. Royal Society of Chemistry, Cambridge, pp 131-161

Scarrow R (2019) Nuanced views Nature Sustainability 2:441-441 https://doi.org/10.1038/s41893019-0318-y

Schleussner CF et al. (2016) Science and policy characteristics of the Paris Agreement temperature goal Nat Clim Chang 6:827-835 https://doi.org/10.1038/nclimate3096

Sharp B (2010) How brands grow: What marketers don't know. Oxford University Press, Melbourne, Australia

Smith JP, Dykema JA, Keith DW (2018) Production of sulfates onboard an aircraft: implications for the cost and feasibility of stratospheric solar geoengineering Earth and Space Science 5:150162 https://doi.org/10.1002/2018EA000370 
Stirling A (2008) "Opening up" and "closing down": Power, participation, and pluralism in the social appraisal of technology Sci Technol Hum Values 33:262-294 https://doi.org/10.1177/0162243907311265

Tollefson J (2018) First sun-dimming experiment will test a way to cool Earth Nature 563:613-615 https://doi.org/10.1038/d41586-018-07533-4

UNEP (2018) The Emissions Gap Report 2018. United Nations Environment Programme, Nairobi

Watts J (2018) Geoengineering may be used to combat global warming, experts say. https://www.theguardian.com/environment/2018/oct/08/geoengineering-global-warming-ipcc.

Wilsdon J, Willis R (2004) See-through science: Why public engagement needs to move upstream. Demos, London

Winickoff DE, Flegal JA, Asrat A (2015) Engaging the Global South on climate engineering research Nat Clim Chang 5:627-634 https://doi.org/10.1038/nclimate2632

Wright M, Klÿn B (1998) Environmental attitude behaviour correlations in 21 countries Journal of Empirical Generalisations in Marketing Science 3:42-60

Wright MJ, Teagle D, Feetham PM (2014) A quantitative evaluation of the public response to climate engineering Nat Clim Chang 4:106-110 https://doi.org/10.1038/nclimate2087 


\section{Acknowledgements}

The work was supported by The Massey University Research Fund (PF, MW). Thanks to Professor Stephen Salter for helpful comments on marine cloud brightening.

\section{Author contributions}

DT conceived the original project, advised on climate engineering approaches and contributed to writing. MW raised research funds, developed the research design, advised on and checked analysis and contributed to writing. PF raised research funds, helped with research design, fieldwork, analysis, and co-wrote the main body. DC developed materials, carried out the analysis, co-wrote the main body and provided the supplementary materials.

\section{Additional information}

Correspondence and requests for materials should be addressed to DC at D.Carlisle@ massey.ac.nz .

\section{Competing financial interests}

The authors declare no competing financial interests. 
Table 1 Approaches for Carbon Dioxide Removal and Solar Radiation Management

\section{Carbon Dioxide Removal}

Biochar

Bioenergy with carbon capture and storage

Direct Air Capture and Carbon Storage

Enhanced Weathering
BECCS

Biomass is combusted to produce renewable energy and carbon dioxide emissions are captured and stored in geological reservoirs.

DACCS Carbon dioxide is filtered from the atmosphere using engineered structures and stored in geological reservoirs.

EW Materials (e.g. silicate minerals) are finely ground to accelerate chemical reactions that remove carbon dioxide from the atmosphere.

\section{Solar Radiation Management}

Marine Cloud

MCB

Brightening

MIS

Tiny seawater droplets are sprayed into low altitude marine clouds to

Mirrors in Space increase their reflectivity.

tospheric Aerosol Space-based materials or structures reflect a portion of incoming sunlight.

Injection

Sulphate particles are spread in the stratosphere to reflect incoming sunlight.

For further reading on CDR and SRM see Lawrence et al. (2018), National Academies of Science (2015a), National Academies of Science (2015b), Royal Society and Royal Academy of Engineering (2018). 
Table 2 Attribute popularity (salience) for climate engineering approaches, as $\%$ of country associations

\begin{tabular}{llllllll}
\hline & & & & & & \\
Rank & Attribute & UK & US & AU & NZ & AU & NZ \\
\hline 1 & Unknown effects & 22 & 24 & 24 & 24 & 24 & 25 \\
2 & Risky & 17 & 19 & 19 & 18 & 16 & 16 \\
3 & Artificial & 13 & 12 & 13 & 14 & 12 & 13 \\
4 & Understandable & 9 & 7 & 7 & 8 & 8 & 7 \\
5 & Environmentally friendly & 8 & 8 & 8 & 7 & 8 & 9 \\
6 & Controllable & 8 & 7 & 7 & 7 & 7 & 8 \\
7 & Long-term sustainability & 7 & 7 & 7 & 7 & 7 & 7 \\
8 & Quick-fix & 6 & 6 & 6 & 6 & 7 & 6 \\
9 & Eyesore & 5 & 5 & 5 & 6 & 6 & 6 \\
10 & Cost effective & 5 & 5 & 5 & 4 & 5 & 3 \\
\end{tabular}


Table 3 Memory associations for climate engineering approaches as counts and as \% net positive associations

\begin{tabular}{|c|c|c|c|c|c|c|c|}
\hline & $\begin{array}{l}\text { Bioenergy } \\
\text { with Carbon } \\
\text { Capture and } \\
\text { Storage }\end{array}$ & $\begin{array}{l}\text { Direct Air } \\
\text { Capture and } \\
\text { Carbon } \\
\text { Storage }\end{array}$ & $\begin{array}{l}\text { Enhanced } \\
\text { Weathering }\end{array}$ & $\begin{array}{l}\text { Marine } \\
\text { Cloud } \\
\text { Brightening }\end{array}$ & $\begin{array}{l}\text { Mirrors in } \\
\text { Space }\end{array}$ & $\begin{array}{l}\text { Stratospheric } \\
\text { Aerosol } \\
\text { Injection }\end{array}$ & Total \\
\hline \multicolumn{8}{|l|}{$\begin{array}{l}\text { Count of associations } \\
(2018)\end{array}$} \\
\hline United Kingdom $(n=751)$ & 1529 & 1513 & 1537 & 1449 & 1527 & 1507 & 9062 \\
\hline United States $(\mathrm{n}=746)$ & 1456 & 1418 & 1481 & 1424 & 1535 & 1503 & 8817 \\
\hline Australia $(n=763)$ & 1618 & 1664 & 1606 & 1597 & 1670 & 1696 & 9851 \\
\hline New Zealand $(n=729)$ & 1683 & 1705 & 1628 & 1689 & 1692 & 1725 & 10122 \\
\hline \multicolumn{8}{|l|}{$\begin{array}{l}\text { Net positive } \\
\text { associations (2018) }\end{array}$} \\
\hline United Kingdom & $4 \%$ & $-8 \%$ & $-11 \%$ & $-39 \%$ & $-48 \%$ & $-62 \%$ & $-27 \%$ \\
\hline United States & $-9 \%$ & $-13 \%$ & $-23 \%$ & $-41 \%$ & $-41 \%$ & $-59 \%$ & $-31 \%$ \\
\hline Australia & $-6 \%$ & $-13 \%$ & $-22 \%$ & $-52 \%$ & $-53 \%$ & $-62 \%$ & $-35 \%$ \\
\hline New Zealand & $-1 \%$ & $-18 \%$ & $-22 \%$ & $-44 \%$ & $-58 \%$ & $-66 \%$ & $-35 \%$ \\
\hline $\begin{array}{l}\text { Net positive } \\
\text { associations (2012) }\end{array}$ & (Biochar) & & & & & & \\
\hline Australia & $-4 \%$ & $-13 \%$ & $-26 \%$ & $-49 \%$ & $-59 \%$ & $-54 \%$ & $-34 \%$ \\
\hline New Zealand & $3 \%$ & $-16 \%$ & $-32 \%$ & $-57 \%$ & $-73 \%$ & $-70 \%$ & $-40 \%$ \\
\hline
\end{tabular}


Table 4 Support for small scale trials 2018

\begin{tabular}{|c|c|c|c|c|c|}
\hline & $\begin{array}{r}\text { Average } \\
(1=\text { Strongly } \\
\text { Agree })\end{array}$ & $\begin{array}{r}\text { Agree } \\
(\%)\end{array}$ & $\begin{array}{r}\text { Neutral } \\
(\%) \\
\end{array}$ & $\begin{array}{r}\text { Disagree } \\
(\%) \\
\end{array}$ & $\begin{array}{r}\text { Average Net } \\
\text { Positive } \\
\text { Associations } \\
(\%)\end{array}$ \\
\hline Bio-Energy with Carbon Capture and Storage & 2.7 & 45 & 33 & 21 & -3 \\
\hline Direct Air Capture with Carbon Storage & 2.7 & 45 & 35 & 21 & -13 \\
\hline Enhanced Weathering & 2.8 & 41 & 34 & 25 & -19 \\
\hline Marine Cloud Brightening & 3.0 & 33 & 36 & 32 & -44 \\
\hline Mirrors in Space & 3.1 & 30 & 35 & 35 & -52 \\
\hline Stratospheric Aerosol Injection & 3.3 & 24 & 34 & 41 & -62 \\
\hline
\end{tabular}




\section{Bio-Energy with Carbon Capture and Storage (BECCS)}

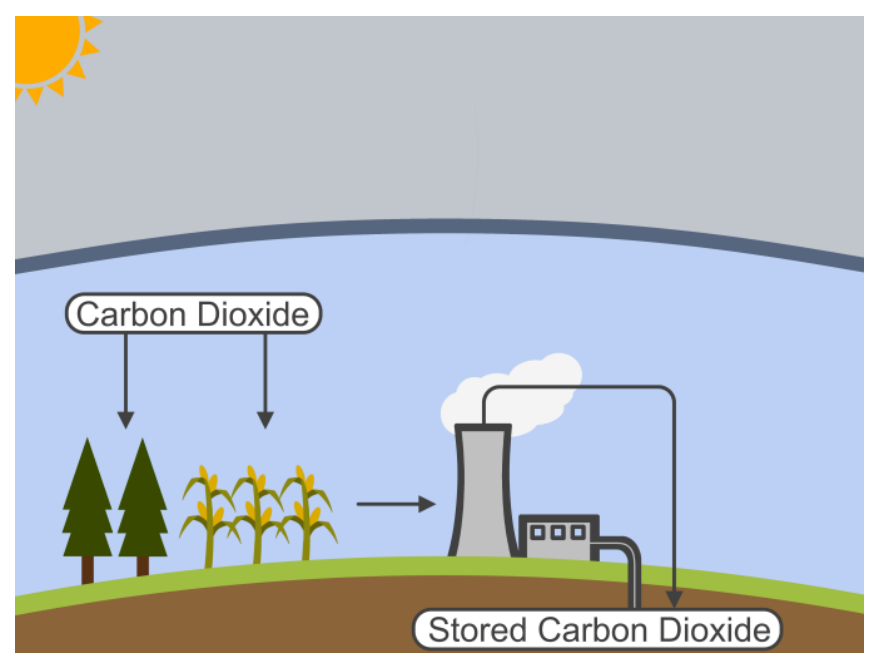

Bio-energy with Carbon Capture and Storage (BECCS) involves growing plants or 'biomass' to remove carbon dioxide from the air. The biomass is combusted to produce renewable energy. The emitted carbon dioxide is captured and stored indefinitely in underground reservoirs. Producing biomass, building infrastructure and transporting carbon incur costs. The land requirements for BECCS could affect food production, biodiversity, water allocation and deforestation. Producing biomass and transporting carbon dioxide require renewable energy sources to ensure that more carbon dioxide is stored than emitted. BECCS could be introduced gradually, however large-scale implementation and infrastructure is required to reduce global temperatures. 


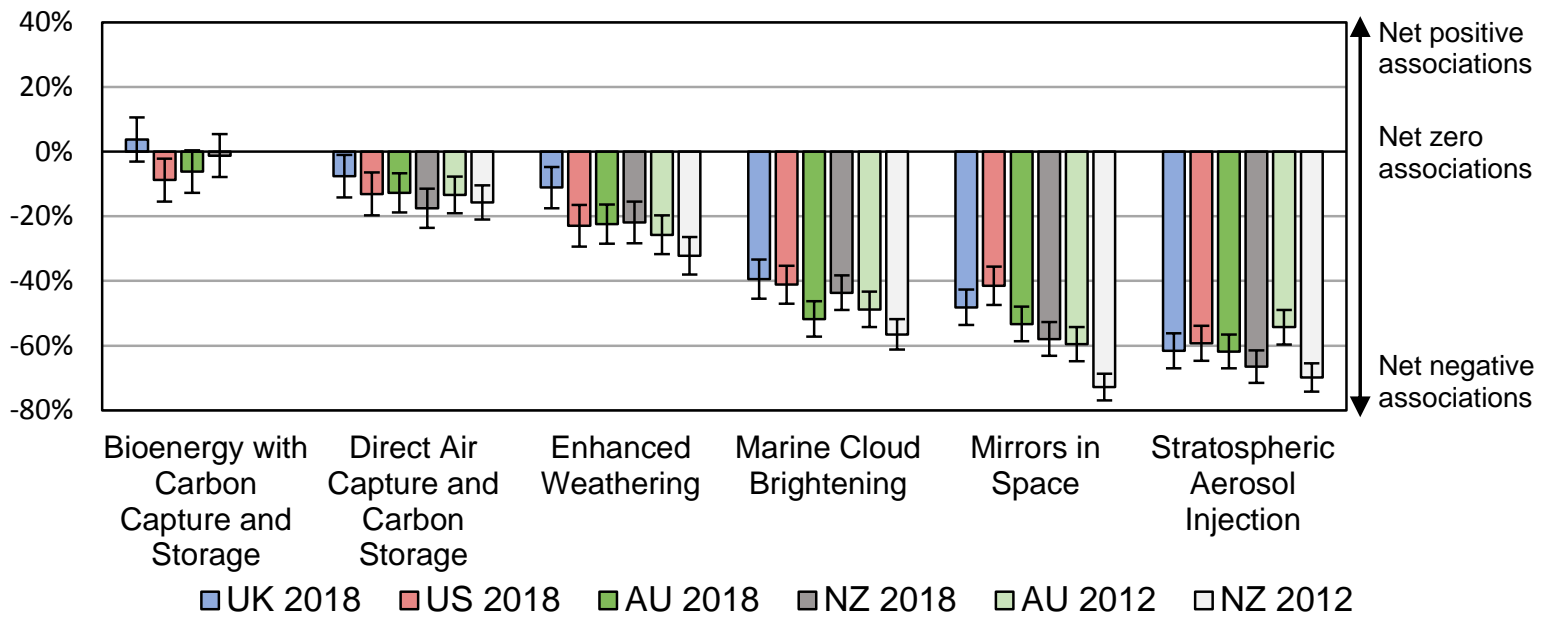



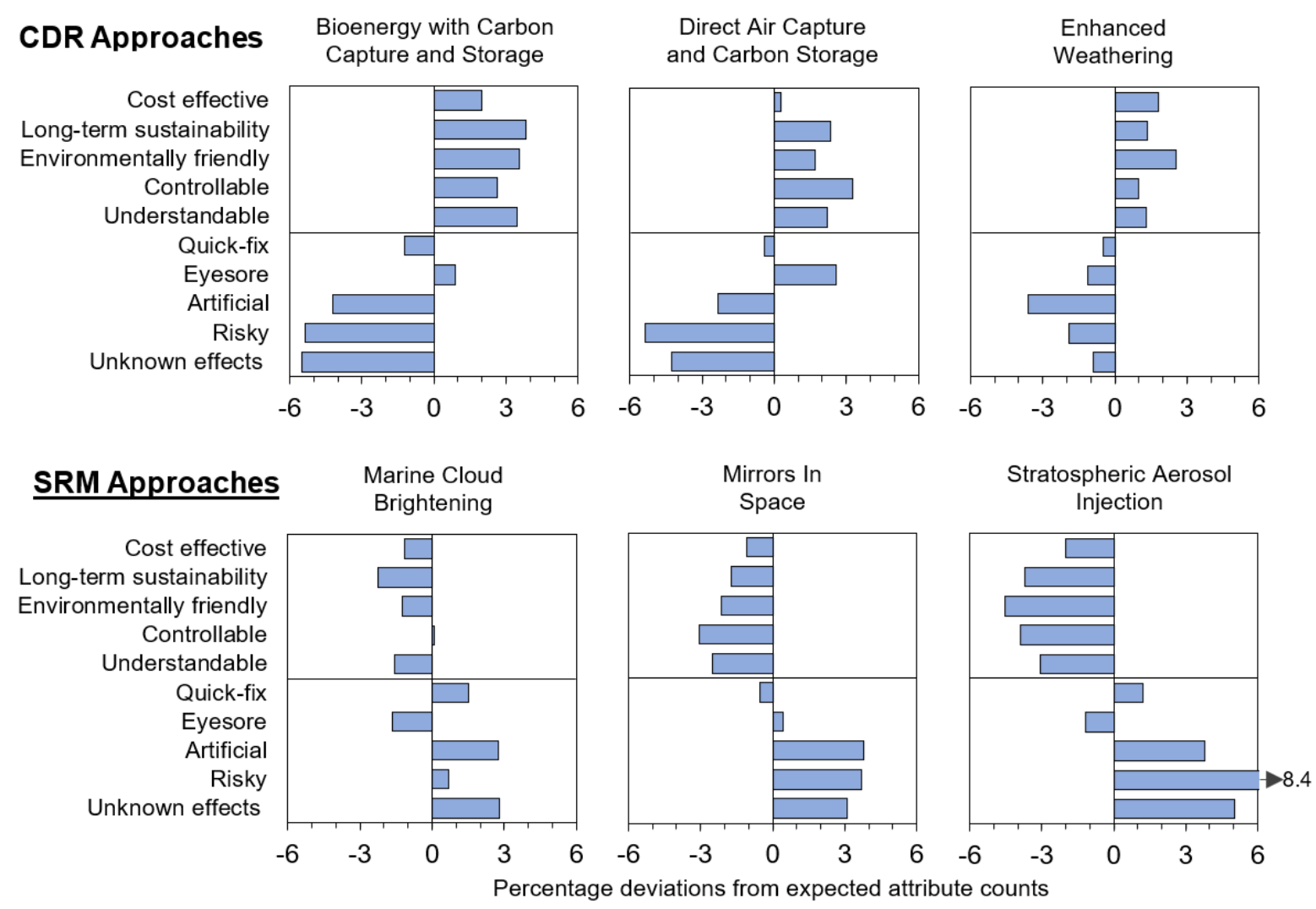


\section{References}

Anderson JR (1983) A spreading activation theory of memory J Verb Learn Verb Be 22:261-295 https://doi.org/10.1016/S0022-5371(83)90201-3

Anderson JR, Bower GH (1974) Human associative memory. John Wiley \& Sons, Washington, DC

Asher H (2017) The problem of nonattitudes. In: Polling and the public: What every citizen should know. 9th edn. Sage, Thousand Oaks, CA, pp 43-72

Australia Bureau of Statistics (2017) 8146.0 - Household use of information technology, Australia, 2016-17. http://www.abs.gov.au/ausstats/abs@.nsf/mf/8146.0. Accessed February 27, 2019

Bawden T (2016) COP21: Paris deal far too weak to prevent devastating climate change, academics warn. https://www.independent.co.uk/environment/climate-change/cop21-paris-deal-far-tooweak-to-prevent-devastating-climate-change-academics-warn-a6803096.html.

Bellamy R, Chilvers J, Vaughan NE (2016) Deliberative mapping of options for tackling climate change: Citizens and specialists ‘open up' appraisal of geoengineering Public Underst Sci 25:269-286 https://doi.org/10.1177/0963662514548628

Bellamy R, Chilvers J, Vaughan NE, Lenton TM (2012) A review of climate geoengineering appraisals Wiley Interdiscip Rev Clim Chang 3:597-615 https://doi.org/10.1002/wcc.197

Bellamy R, Chilvers J, Vaughan NE, Lenton TM (2013) 'Opening up' geoengineering appraisal: Multi-criteria mapping of options for tackling climate change Glob Environ Chang 23:926937 https://doi.org/10.1016/j.gloenvcha.2013.07.011

Bellamy R, Healey P (2018) ‘Slippery slope' or 'uphill struggle’? Broadening out expert scenarios of climate engineering research and development Environ Sci Pol 83:1-10 https://doi.org/10.1016/j.envsci.2018.01.021

Bellamy R, Lezaun J (2017) Crafting a public for geoengineering Public Underst Sci 26:402-417 https://doi.org/10.1177/0963662515600965

Bellamy R, Lezaun J, Palmer J (2019) Perceptions of bioenergy with carbon capture and storage in different policy scenarios Nat Commun 10:743 https://doi.org/10.1038/s41467-019-08592-5 
Biermann F, Möller I (2019) Rich man's solution? Climate engineering discourses and the marginalization of the Global South Int Environ Agreem-P 19:151-167 https://doi.org/10.1007/s10784-019-09431-0

Braun C, Merk C, Pönitzsch G, Rehdanz K, Schmidt U (2018a) Public perception of climate engineering and carbon capture and storage in Germany: survey evidence Clim Policy 18:471-484 https://doi.org/10.1080/14693062.2017.1304888

Braun C, Rehdanz K, Schmidt U (2018b) Exploring public perception of environmental technology over time J Environ Plann Man 61:143-160 https://doi.org/10.1080/09640568.2017.1291414

Burns E, Flegal JA, Keith DW, Mahajan A, Tingley D, Wagner G (2016) What do people think when they think about solar geoengineering? A review of empirical social science literature, and prospects for future research Earth's Future 4:536-542 https://doi.org/10.1002/2016EF000461

Chilvers J (2009) Deliberative and participatory approaches in environmental geography. In: Noel Castree DD, Diana Liverman, Bruce Rhoads (ed) A Companion to Environmental Geography. John Wiley \& Sons Ltd, West Sussex, UK,

Colvin RM et al. (2019) Learning from the climate change debate to avoid polarisation on negative emissions Environ Commun https://doi.org/10.1080/17524032.2019.1630463

Corner A, Parkhill KA, Pidgeon NF (2011) 'Experiment Earth?' Reflections on a public dialogue on geoengineering: Reflections on a public dialogue on geoengineering

Corner A, Pidgeon NF (2010) Geoengineering the climate: The social and ethical implications Environment 52:24-37 https://doi.org/10.1080/00139150903479563

Corner A, Pidgeon NF (2015) Like artificial trees? The effect of framing by natural analogy on public perceptions of geoengineering Climatic Change 130:425-438 https://doi.org/10.1007/s10584014-1148-6

Corner A, Pidgeon NF, Parkhill KA (2012) Perceptions of geoengineering: Public attitudes, stakeholder perspectives, and the challenge of 'upstream' engagement Wiley Interdiscip Rev Clim Chang 3:451-466 https://doi.org/10.1002/wcc.176

Cummings CL, Lin SH, Trump BD (2017) Public perceptions of climate geoengineering: a systematic review of the literature Clim Res 73:247-264 https://doi.org/10.3354/cr01475 
Díaz Andrade A, Hedges MR, Karimikia H, Techatassanasoontorn A (2018) World Internet Project: The Internet in New Zealand 2017. New Zealand Work Research Institute, Auckland Doyle A (2017) Climate scientists sucking carbon dioxide from air and dimming sun's rays with chemicals to cool planet. https://www.independent.co.uk/environment/geo-engineeringtechnology-climate-change-environment-climeworks-carbon-dioxide-chemicals-dimminga7860356.html.

Dunlap RE, Van Liere KD, Mertig AG, Jones RE (2000) New trends in measuring environmental attitudes: measuring endorsement of the new ecological paradigm: a revised NEP scale J Soc Issues 56:425-442 https://doi.org/10.1111/0022-4537.00176

Dütschke E, Wohlfarth K, Höller S, Viebahn P, Schumann D, Pietzner K (2016) Differences in the public perception of CCS in Germany depending on $\mathrm{CO} 2$ source, transport option and storage location Int J Greenh Gas Con 53:149-159 https://doi.org/10.1016/j.ijggc.2016.07.043

Fiorino DJ (1990) Citizen participation and environmental risk: A survey of institutional mechanisms Sci Technol Hum Values 15:226-243 https://doi.org/10.1177/016224399001500204

Heyward C (2013) Situating and abandoning geoengineering: a typology of five responses to dangerous climate change Polit Sci Polit 46:23-27 https://doi.org/10.1017/S1049096512001436

Horton JB (2015) Why we should treat SRM and CDR separately. https://ceassessment.org/why-weshould-treat-srm-and-cdr-separately-joshua-b-horton/.

IPCC (2014) Climate Change 2014: Synthesis Report. Contribution of Working Groups I, II and III to the Fifth Assessment Report of the Intergovernmental Panel on Climate Change. R.K. Pachauri and L.A. Meyer (eds), IPCC, Geneva, Switzerland

Irvine P, Emanuel K, He J, Horowitz LW, Vecchi G, Keith D (2019) Halving warming with idealized solar geoengineering moderates key climate hazards Nat Clim Chang 9:295-299 https://doi.org/10.1038/s41558-019-0398-8

Ki-moon B (2019) Governing Geoengineering. https://www.projectsyndicate.org/commentary/climate-change-geoengineering-technologies-governance-by-banki-moon-2019-03. 
Kravitz B et al. (2019) Holistic assessment of SO2 injections using CESM1 (WACCM): Introduction to the special issue J Geophys Res-Atmos 124:444-450 https://doi.org/10.1029/2018JD029293

Kravitz B et al. (2018) The Geoengineering Model Intercomparison Project-introduction to the second special issue Atmos Chem Phys https://doi.org/10.5194/acp-special_issue376-preface Lawrence MG et al. (2018) Evaluating climate geoengineering proposals in the context of the Paris Agreement temperature goals Nat Commun 9:3734 https://doi.org/10.1038/s41467-018$05938-3$

Lomax G, Workman M, Lenton T, Shah N (2015) Reframing the policy approach to greenhouse gas removal technologies Energy Policy 78:125-136 https://doi.org/10.1016/j.enpol.2014.10.002

MacMartin DG, Ricke KL, Keith DW (2018) Solar geoengineering as part of an overall strategy for meeting the 1.5 C Paris target Phil Trans A Math Phys Eng Sci 376 https://doi.org/10.1098/rsta.2016.0454

Merk C, Pönitzsch G (2017) The role of affect in attitude formation toward new technologies: The case of stratospheric aerosol injection Risk Anal 37:2289-2304 https://doi.org/10.1111/risa.12780

Merk C, Pönitzsch G, Kniebes C, Rehdanz K, Schmidt U (2015) Exploring public perceptions of stratospheric sulfate injection Climatic Change 130:299-312 https://doi.org/10.1007/s10584$014-1317-7$

Minx JC et al. (2018) Negative emissions - Part 1: Research landscape and synthesis Environ Res Lett 13 https://doi.org/10.1088/1748-9326/aabf9b

National Academies of Science (2015a) Climate intervention: carbon dioxide removal and reliable sequestration. National Academies Press, Washington, DC

National Academies of Science (2015b) Climate Intervention: reflecting sunlight to cool Earth. National Academy Press, Washington, DC

Office for National Statistics (2018) Internet access - households and individuals, Great Britain: 2018. https://www.ons.gov.uk/peoplepopulationandcommunity/householdcharacteristics/homeintern 
etandsocialmediausage/bulletins/internetaccesshouseholdsandindividuals/2018. Accessed 27 February 2019

Rayner S, Heyward C, Kruger T, Pidgeon NF, Redgwell C, Savulescu J (2013) The Oxford Principles Climatic Change 121:499-512 https://doi.org/10.1007/s10584-012-0675-2

Rogers-Hayden T, Pidgeon NF (2007) Moving engagement “upstream"? Nanotechnologies and the Royal Society and Royal Academy of Engineering's inquiry Public Underst Sci 16:345-364 https://doi.org/10.1177/0963662506076141

Rogers B, Ryals L (2007) Using the repertory grid to access the underlying realities in key account relationships Int J Market Res 49:595-612 https://doi.org/10.1177/147078530704900506

Romaniuk J (2013) Modeling mental market share J Bus Res 66:188-195 https://doi.org/10.1016/j.jbusres.2012.07.012

Rowe G, Frewer LJ (2005) A typology of public engagement mechanisms 30:251-290 https://doi.org/10.1177/0162243904271724

Royal Society, Royal Academy of Engineering (2018) Greenhouse gas removal.

Ryan C, Lewis JM (2017) Computer and internet use in the United States: 2015. U.S. Census Bureau, Washington, DC

Salter S, Stevenson T, Tsiamis A (2014) Engineering ideas for brighter clouds. In: Hester RE, Harrison RM (eds) Geoengineering of the climate system., vol 38. Issues in Environmental Science and Technology. Royal Society of Chemistry, Cambridge, pp 131-161

Scarrow R (2019) Nuanced views Nature Sustainability 2:441-441 https://doi.org/10.1038/s41893019-0318-y

Schleussner CF et al. (2016) Science and policy characteristics of the Paris Agreement temperature goal Nat Clim Chang 6:827-835 https://doi.org/10.1038/nclimate3096

Sharp B (2010) How brands grow: What marketers don't know. Oxford University Press, Melbourne, Australia

Smith JP, Dykema JA, Keith DW (2018) Production of sulfates onboard an aircraft: implications for the cost and feasibility of stratospheric solar geoengineering Earth and Space Science 5:150162 https://doi.org/10.1002/2018EA000370 
Stirling A (2008) "Opening up" and "closing down": Power, participation, and pluralism in the social appraisal of technology Sci Technol Hum Values 33:262-294 https://doi.org/10.1177/0162243907311265

Tollefson J (2018) First sun-dimming experiment will test a way to cool Earth Nature 563:613-615 https://doi.org/10.1038/d41586-018-07533-4

UNEP (2018) The Emissions Gap Report 2018. United Nations Environment Programme, Nairobi

Watts J (2018) Geoengineering may be used to combat global warming, experts say. https://www.theguardian.com/environment/2018/oct/08/geoengineering-global-warming-ipcc.

Wilsdon J, Willis R (2004) See-through science: Why public engagement needs to move upstream. Demos, London

Winickoff DE, Flegal JA, Asrat A (2015) Engaging the Global South on climate engineering research Nat Clim Chang 5:627-634 https://doi.org/10.1038/nclimate2632

Wright M, Klÿn B (1998) Environmental attitude behaviour correlations in 21 countries Journal of Empirical Generalisations in Marketing Science 3:42-60

Wright MJ, Teagle D, Feetham PM (2014) A quantitative evaluation of the public response to climate engineering Nat Clim Chang 4:106-110 https://doi.org/10.1038/nclimate2087 


\section{The public remain uninformed and wary of climate engineering}

\section{Supplementary information}

This supplementary information provides tabular and graphical details of method that are omitted from the main manuscript for reasons of space, as well as additional materials to enable replication by other researchers. The supplementary information is divided into six sections:

1. Qualitative Phase - Sample Composition

2. Quantitative Phase - Sample Composition

3. Quantitative Phase - Materials \& Method

4. Quantitative Phase - Analysis of Net Positive Variable

5. Quantitative Phase - Comparisons between Samples

6. Quantitative Phase-Construction of Concept Maps

\section{Qualitative Phase - Sample Composition}

\begin{tabular}{|c|c|c|c|}
\hline \multicolumn{4}{|c|}{ Supplementary Table 1 | New Zealand Qualitative Demographics $(n=15)$} \\
\hline Subject & Gender & Age & Occupation \\
\hline 1 & Male & 22 & Architectural Draftsman \\
\hline 2 & Female & 22 & Student \\
\hline 3 & Male & 22 & Stunt Performer \\
\hline 4 & Female & 57 & Administration \\
\hline 5 & Male & 55 & Financial Advisor \\
\hline 6 & Female & 30 & Post-Doctoral Fellow \\
\hline 7 & Female & 25 & Sales Representative \\
\hline 8 & Female & 25 & Marketing/Events \\
\hline 9 & Male & 47 & Unemployed \\
\hline 10 & Female & 21 & Rural Consultant \\
\hline 11 & Female & 54 & School Administrator \\
\hline 12 & Female & 55 & School Administrator \\
\hline 13 & Male & 63 & University Academic \\
\hline 14 & Male & 29 & Accommodation Manager \\
\hline 15 & Male & 27 & Student \\
\hline
\end{tabular}




\section{Quantitative Phase - Sample Composition}

Supplementary Tables 2, 3, 4 and 5 report the demographic breakdown of the quantitative samples along with comparative census data or similar independent population estimates for gender, age and political support. In all four quantitative samples participants are broadly spread across demographic groups, with slight under-representation of under 25-year olds and irregular slight over-representation of over 65-year old age groups in the UK, US, AU and NZ samples. The UK sample shows a slight over-representation of the lowest income level and NZ shows slight under-representation of some lower incomes as well as slight over-representation of some higher incomes. Political party support is slightly under-estimated for the Democrats in the US and National in NZ. The sample characteristics for each country nonetheless show a satisfactory spread of demographics with overall only small deviations from census data or similar independent population estimates. The sample composition is acceptable for the purposes of this research. 


\section{Supplementary Table 2 | UK Demographics}

\begin{tabular}{|c|c|c|}
\hline & UK Sample $(n=751)$ & UK Census ${ }^{1,2}$ \\
\hline Age (Years)* & $\%$ & $\%$ \\
\hline $18-24$ & 3 & 13 \\
\hline $25-34$ & 16 & 18 \\
\hline $35-44$ & 19 & 19 \\
\hline $45-54$ & 17 & 19 \\
\hline $55-64$ & 18 & 16 \\
\hline $65-74$ & 15 & 12 \\
\hline $75-80$ & 13 & 5 \\
\hline \multicolumn{3}{|l|}{ Gender } \\
\hline Male & 50 & 49 \\
\hline \multirow[t]{2}{*}{ Female } & 50 & 51 \\
\hline & UK Sample $(n=751)$ & $\begin{array}{l}\text { Office for National } \\
\text { Statistics }(2018)^{3}\end{array}$ \\
\hline \multicolumn{3}{|l|}{ Household Annual Income (GBP£) } \\
\hline Less than $£ 12,999$ & 16 & 6 \\
\hline$£ 13,000-£ 18,999$ & 9 & 11 \\
\hline$£ 19,000-£ 25,999$ & 14 & 16 \\
\hline$£ 26,000-£ 31,999$ & 15 & 13 \\
\hline$£ 32,000-£ 47,999$ & 23 & 26 \\
\hline$£ 48,000-£ 63,999$ & 11 & 13 \\
\hline$£ 64,000-£ 95,999$ & 7 & 11 \\
\hline \multirow[t]{2}{*}{ More than $£ 96,000$} & 4 & 5 \\
\hline & UK Sample $(n=751)$ & $\begin{array}{c}\text { YouGov } \\
(\text { Nov, 2018) } \\
\end{array}$ \\
\hline \multicolumn{3}{|l|}{ Political Support*** } \\
\hline Conservative Party & 40 & 39 \\
\hline Labour Party & 32 & 36 \\
\hline Liberal Democrats & 10 & 8 \\
\hline Other/Independent & 17 & 14 \\
\hline \multicolumn{3}{|l|}{ Education } \\
\hline Completed Postgraduate (e.g. Masters or PhD) & 8 & \\
\hline Completed undergraduate (e.g. Bachelor's Degree) & 27 & \\
\hline Some tertiary education (e.g. Certificate or Diploma) & 17 & \\
\hline \multicolumn{3}{|l|}{ Trade or Technical Qualification (e.g. } \\
\hline Apprenticeship, Industry Qualification, etc.) & 15 & \\
\hline Graduated Secondary School (High School) & 30 & \\
\hline Graduated Primary School (Elementary School) & 3 & \\
\hline \multicolumn{3}{|l|}{ Location } \\
\hline More than 5 million people (Major Urban Area) & 8 & \\
\hline 1 million to 4.9 million people & 5 & \\
\hline 100,000 to 999,999 people & 17 & \\
\hline 50,000 to 99,999 people & 16 & \\
\hline 10,000 to 49,999 people & 23 & \\
\hline 1,000 to 9,999 people & 20 & \\
\hline 200 to 999 people & 7 & \\
\hline Less than 200 people (Rural Area) & 4 & \\
\hline
\end{tabular}

*Census data for age is calculated as the proportion of the 18 - 80 age group.

**Political support is calculated excluding invalid responses. 


\begin{tabular}{|c|c|c|}
\hline & US Sample $(n=746)$ & $\begin{array}{c}\text { Annual Estimates of } \\
\text { the Resident } \\
\text { Population }(2017)^{5}\end{array}$ \\
\hline Age (Years)* & $\%$ & $\%$ \\
\hline $18-24$ & 4 & 13 \\
\hline $25-34$ & 14 & 19 \\
\hline $35-44$ & 19 & 17 \\
\hline $45-54$ & 17 & 18 \\
\hline $55-64$ & 18 & 17 \\
\hline $65-74$ & 16 & 12 \\
\hline $75-80$ & 13 & 4 \\
\hline \multicolumn{3}{|l|}{ Gender } \\
\hline Male & 49 & 49 \\
\hline \multirow[t]{2}{*}{ Female } & 51 & 51 \\
\hline & US Sample $(n=746)$ & $\begin{array}{c}\text { Current Population } \\
\text { Survey }(2017)^{6}\end{array}$ \\
\hline \multicolumn{3}{|l|}{ Household Annual Income (USD\$) } \\
\hline Less than $\$ 10,000$ & 8 & 4 \\
\hline$\$ 10,000$ to $\$ 19,999$ & 8 & 5 \\
\hline$\$ 20,000$ to $\$ 29,999$ & 10 & 8 \\
\hline$\$ 30,000$ to $\$ 39,999$ & 9 & 8 \\
\hline$\$ 40,000$ to $\$ 49,999$ & 9 & 8 \\
\hline$\$ 50,000$ to $\$ 59,999$ & 7 & 7 \\
\hline$\$ 60,000$ to $\$ 69,999$ & 8 & 7 \\
\hline$\$ 70,000$ to $\$ 99,999$ & 18 & 17 \\
\hline$\$ 100,000$ to $\$ 149,999$ & 15 & 17 \\
\hline$\$ 150,000$ to $\$ 199,999$ & 3 & 9 \\
\hline \multirow{2}{*}{ More than $\$ 200,000$} & 4 & 10 \\
\hline & US Sample $(n=746)$ & $\begin{array}{c}\text { SRSS (October } \\
2018)^{7}\end{array}$ \\
\hline \multicolumn{3}{|l|}{ Political Support** } \\
\hline Republican Party & 45 & 42 \\
\hline Democratic Party & 49 & 56 \\
\hline Other/Independent & 6 & 2 \\
\hline \multicolumn{3}{|l|}{ Education } \\
\hline Completed Postgraduate (e.g. Masters or PhD) & 19 & \\
\hline Completed undergraduate (e.g. Bachelor's Degree) & 29 & \\
\hline \multicolumn{3}{|l|}{ Some tertiary education (e.g. Certificate or } \\
\hline Diploma) & 17 & \\
\hline \multicolumn{3}{|l|}{ Trade or Technical Qualification (e.g. } \\
\hline Apprenticeship, Industry Qualification, etc.) & 9 & \\
\hline Graduated Secondary School (High School) & 23 & \\
\hline Graduated Primary School (Elementary School) & 2 & \\
\hline \multicolumn{3}{|l|}{ Location } \\
\hline More than 5 million people (Major Urban Area) & 5 & \\
\hline 1 million to 4.9 million people & 11 & \\
\hline 100,000 to 999,999 people & 17 & \\
\hline 50,000 to 99,999 people & 16 & \\
\hline 10,000 to 49,999 people & 21 & \\
\hline 1,000 to 9,999 people & 10 & \\
\hline 200 to 999 people & 8 & \\
\hline Less than 200 people (Rural Area) & 11 & \\
\hline
\end{tabular}

*Data for age is calculated as the proportion of the $18-80$ age group.

**Political support is calculated excluding invalid responses. 


\begin{tabular}{|c|c|c|}
\hline \multicolumn{3}{|c|}{ Supplementary Table 4 | Australian Demographics } \\
\hline & AU Sample $(n=763)$ & AU Census ${ }^{8}$ \\
\hline Age (Years)* & $\%$ & $\%$ \\
\hline $18-24$ & 5 & 12 \\
\hline $25-34$ & 13 & 19 \\
\hline $35-44$ & 20 & 18 \\
\hline $45-54$ & 16 & 18 \\
\hline $55-64$ & 20 & 16 \\
\hline $65-74$ & 25 & 12 \\
\hline $75-80$ & 4 & 4 \\
\hline \multicolumn{3}{|l|}{ Gender } \\
\hline Male & 48 & 49 \\
\hline Female & 52 & 51 \\
\hline \multicolumn{3}{|l|}{ Household Weekly Income (AUSD\$) } \\
\hline Less than $\$ 149$ & 4 & 3 \\
\hline$\$ 150-\$ 299$ & 4 & 3 \\
\hline$\$ 300-\$ 399$ & 5 & 4 \\
\hline$\$ 400-\$ 499$ & 8 & 9 \\
\hline$\$ 500-\$ 649$ & 10 & 6 \\
\hline$\$ 650-\$ 799$ & 8 & 9 \\
\hline$\$ 800-\$ 999$ & 9 & 9 \\
\hline$\$ 1,000-\$ 1,249$ & 12 & 11 \\
\hline$\$ 1,250-\$ 1,499$ & 9 & 10 \\
\hline$\$ 1,500-\$ 1,749$ & 8 & 8 \\
\hline$\$ 1,750-\$ 1,999$ & 6 & 7 \\
\hline$\$ 2,000-\$ 2,999$ & 10 & 14 \\
\hline \multirow[t]{2}{*}{ More than $\$ 3,000$} & 9 & 9 \\
\hline & AU Sample $(n=763)$ & $\begin{array}{l}\text { Essential Research } \\
\text { (December 2018) }^{9}\end{array}$ \\
\hline \multicolumn{3}{|l|}{ Political Support*** } \\
\hline Australian Labor Party & 43 & 39 \\
\hline Liberal Party of Australia & 33 & 34 \\
\hline National Party of Australia & 7 & 4 \\
\hline Pauline Hanson's One Nation & 5 & 6 \\
\hline Australian Greens & 6 & 10 \\
\hline Independent/Other & 7 & 7 \\
\hline \multicolumn{3}{|l|}{ Education } \\
\hline Completed Postgraduate (e.g. Masters or PhD) & 9 & \\
\hline \multicolumn{3}{|l|}{ Completed undergraduate (e.g. Bachelor's } \\
\hline Degree) & 23 & \\
\hline \multicolumn{3}{|l|}{ Some tertiary education (e.g. Certificate or } \\
\hline Diploma) & 25 & \\
\hline \multicolumn{3}{|l|}{ Trade or Technical Qualification (e.g. } \\
\hline Apprenticeship, Industry Qualification, etc.) & 12 & \\
\hline Graduated Secondary School (High School) & 27 & \\
\hline Graduated Primary School (Elementary School) & 4 & \\
\hline \multicolumn{3}{|l|}{ Location } \\
\hline More than 5 million people (Major Urban Area) & 17 & \\
\hline 1 million to 4.9 million people & 22 & \\
\hline 100,000 to 999,999 people & 15 & \\
\hline 50,000 to 99,999 people & 10 & \\
\hline 10,000 to 49,999 people & 16 & \\
\hline 1,000 to 9,999 people & 15 & \\
\hline 200 to 999 people & 3 & \\
\hline Less than 200 people (Rural Area) & 3 & \\
\hline
\end{tabular}

*Census data for age is calculated as the proportion of the 18 - 80 age group.

**Political support is calculated excluding invalid responses. 


\section{Supplementary Table 5 | NZ Demographics}

\begin{tabular}{|c|c|c|}
\hline & NZ Sample $(n=729)$ & NZ Census ${ }^{10-13}$ \\
\hline Age (Years)* & $\%$ & $\%$ \\
\hline $18-24$ & 6 & 13 \\
\hline $25-34$ & 13 & 17 \\
\hline $35-44$ & 17 & 19 \\
\hline $45-54$ & 17 & 20 \\
\hline $55-64$ & 17 & 16 \\
\hline $65-74$ & 16 & 11 \\
\hline $75-80$ & 14 & 4 \\
\hline \multicolumn{3}{|l|}{ Gender } \\
\hline Male & 50 & 49 \\
\hline Female & 50 & 51 \\
\hline \multicolumn{3}{|l|}{ Household Annual Income (NZD\$) } \\
\hline Less than $\$ 10,000$ & 3 & 20 \\
\hline$\$ 10,001-\$ 20,000$ & 6 & 18 \\
\hline$\$ 20,001-\$ 30,000$ & 14 & 14 \\
\hline$\$ 30,001-\$ 40,000$ & 13 & 12 \\
\hline$\$ 40,001-\$ 50,000$ & 12 & 10 \\
\hline$\$ 50,001-\$ 60,000$ & 8 & 7 \\
\hline$\$ 60,001-\$ 70,000$ & 7 & 6 \\
\hline$\$ 70,001-\$ 100,000$ & 17 & 8 \\
\hline$\$ 100,001-\$ 150,000$ & 15 & 4 \\
\hline \multirow{2}{*}{ More than $\$ 150,001$} & 6 & 2 \\
\hline & NZ Sample $(n=729)$ & $\begin{array}{c}\text { Colmar Brunton } \\
\text { (November 2018) }^{14}\end{array}$ \\
\hline \multicolumn{3}{|l|}{ Political Support*** } \\
\hline New Zealand National Party & 35 & 46 \\
\hline The New Zealand Labour Party & 40 & 43 \\
\hline Green Party of Aotearoa New Zealand & 8 & 5 \\
\hline New Zealand First & 9 & 4 \\
\hline Other & 1 & 2 \\
\hline \multicolumn{3}{|l|}{ Education } \\
\hline Completed Postgraduate (e.g. Masters or PhD) & 10 & \\
\hline \multicolumn{3}{|l|}{ Completed undergraduate (e.g. Bachelor's } \\
\hline Degree) & 25 & \\
\hline \multicolumn{3}{|l|}{ Some tertiary education (e.g. Certificate or } \\
\hline Diploma) & 24 & \\
\hline \multicolumn{3}{|l|}{ Trade or Technical Qualification (e.g. } \\
\hline Apprenticeship, Industry Qualification, etc.) & 13 & \\
\hline Graduated Secondary School (High School) & 25 & \\
\hline Graduated Primary School (Elementary School) & 4 & \\
\hline \multicolumn{3}{|l|}{ Location } \\
\hline More than $1,000,000$ people (Major Urban Area) & 23 & \\
\hline 100,000 to 999,999 people & 22 & \\
\hline 30,000 to 99,999 people & 18 & \\
\hline 10,000 to 29,999 people & 14 & \\
\hline 1,000 to 9,999 people & 13 & \\
\hline 200 to 999 people & 3 & \\
\hline Less than 200 people (Rural Area) & 6 & \\
\hline
\end{tabular}

*Census data for age is calculated as the proportion of the 18 - 80 age group.

**Political support is calculated excluding invalid responses. 


\section{Quantitative Phase - Materials \& Method}

\subsection{Introduction and warmup questions}

\section{Supplementary Figure 1 | Survey introduction and concept introduction}

Questionnaire Page 1. Survey Introduction and warm up questions

Global warming refers to the idea that the world's average temperature has been increasing, may increase more in the future, and is causing changes to the world's climate. These changes have been attributed to increasing greenhouse gas emissions such as carbon dioxide.

Please read the statements below and then indicate whether you agree or disagree by clicking

ONE button beside each statement

\begin{tabular}{|c|c|c|c|c|c|}
\hline & $\begin{array}{c}\text { Strongly } \\
\text { agree }\end{array}$ & Agree & Neutral & Disagree & $\begin{array}{l}\text { Strongly } \\
\text { disagree }\end{array}$ \\
\hline $\begin{array}{l}\text { We should try to } \\
\text { reduce global } \\
\text { warming. }\end{array}$ & 0 & 0 & 0 & 0 & 0 \\
\hline $\begin{array}{l}\text { Global warming is } \\
\text { causing changes to the } \\
\text { climate. }\end{array}$ & 0 & 0 & 0 & 0 & 0 \\
\hline $\begin{array}{l}\text { Humans are primarily } \\
\text { responsible for global } \\
\text { warming. }\end{array}$ & 0 & 0 & 0 & 0 & 0 \\
\hline
\end{tabular}

Questionnaire Page 2. Concept Introduction

In response to global warming, 196 countries adopted the 2015 Paris Agreement under the United Nations Framework Convention on Climate Change. The aim of the agreement is to limit the global increase in temperatures to below $2^{\circ}$ Celsius.

Alongside ways for adapting to global warming, governments and scientists are considering a range of possible solutions for achieving the $2^{\circ} \mathrm{C}$ goal. Some proposals include reducing global emissions, removing carbon dioxide from the air, or reflecting sunlight back into space.

We would like to know what you think about some of these proposals for removing carbon dioxide and reflecting sunlight. In the following pages we will present six proposals and ask some questions about each one. Please read the description and tick the boxes that you think apply. There are no right or wrong answers in this survey. Rather we are interested in your opinion 


\section{Supplementary Figure 2 | Concept Boards}

Bio-Energy with Carbon Capture and Storage (BECCS)

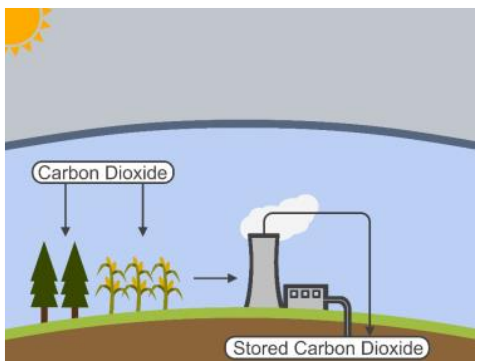

Bio-energy with Carbon Capture and Storage (BECCS) involves growing plants or 'biomass' to remove carbon dioxide from the air. The biomass is combusted to produce renewable energy. The emitted carbon dioxide is captured and stored indefinitely in underground reservoirs. Producing biomass, building infrastructure, and transporting carbon incur costs. The land requirements for BECCS could affect food production, biodiversity, water allocation, and deforestation. Producing and transporting biomass require renewable energy sources to ensure that more carbon dioxide is stored than emitted. BECCS could be introduced gradually, however, large-scale implementation and infrastructure is required to reduce global temperatures.

Enhanced Weathering

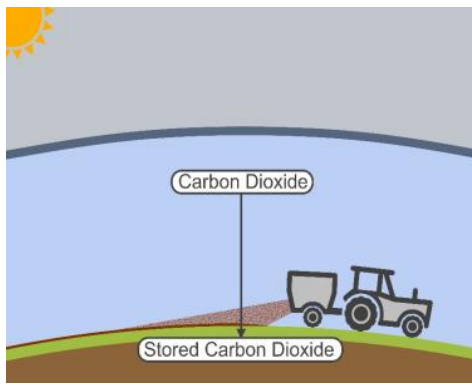

Certain rocks react with atmospheric carbon dioxide to break down or 'weather'. This reaction forms new minerals that store carbon indefinitely. Crushing and spreading the rocks accelerates carbon dioxide removal, improves soil quality, may reduce mine wastes, and could reduce ocean acidification if washed out to sea. Enhanced Weathering requires land and could affect biodiversity, human heath, and leach heavy metals into soils. Mining, transporting, and spreading biodiversity, human health, and leach heavy metals into soils. Mining, transporting, and spreading than emitted. Enhanced Weathering could be introduced gradually, however, large-scale implementation is required to reduce global temperatures.

Mirrors in Space

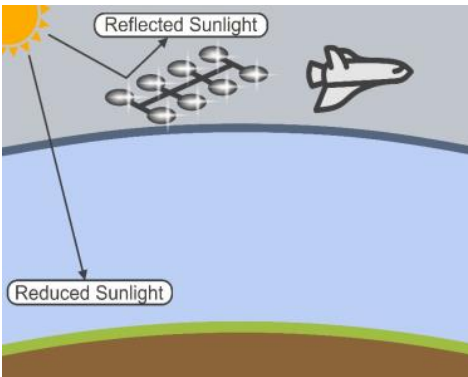

Mirrors in Space involves positioning reflective structures to orbit the Earth. These structures intercept and reflect some sunlight back into space, rapidly cooling the Earth. Space-craft would be used to position the materials. Space transportation incurs costs and would require large-scale investment, research, and development. Implementation would increase the number of orbital objects and could produce an uneven cooling effect, alter rainfall patterns, and change the appearance of the night sky. Large-scale implementation is required and temperatures would appearance of the night sky. Large-scale implementation is required and temperatures would revert to pre-application levels if the structures
decades and may require international agreements.
Direct Air Capture and Carbon Storage (DACCS)

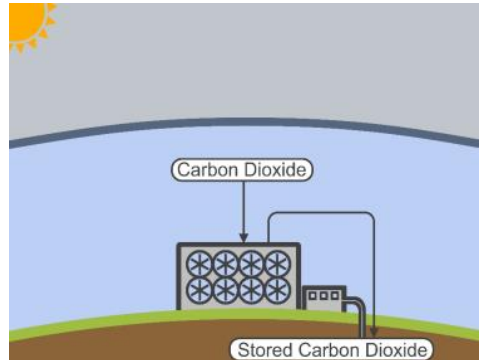

Direct Air Capture and Carbon Storage (DACCS) involves building structures that filter carbon dioxide from the air. Carbon dioxide is captured, transported, and stored indefinitely in underground reservoirs. Structures can be located anywhere and would target areas with suitable costs. Powering the air capture structures and transporting carbon dioxide requires renewable energy sources to ensure that more carbon is stored than emitted. Direct Air Capture cowld be introduced gradully, however, large scale impled reduce global temperatures.

Marine Cloud Brightening

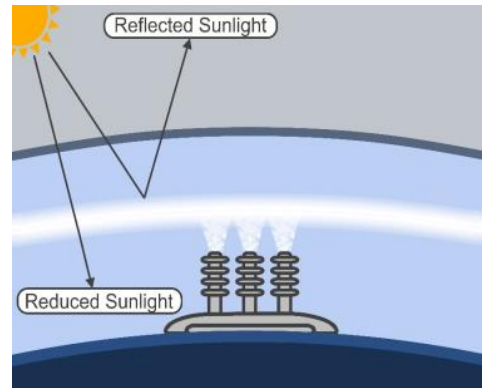

Marine Cloud Brightening involves automated ships spraying small seawater droplets above the ocean in targeted areas. Vapour forms around these droplets, increasing the number and brightness of clouds reflecting some sunlight back into space. Developing and building fleets of spraying vessels incurs costs. Cloud brightening is restrictod to marine areas and may alter loca rainfall patterns. Changes in light, ocean temperature, and currents may affect marine nutrien growth. Large-scale implementation and continuous applications are required to maintain the cooling effect. Temperatures would quickly revert to pre-application levels if stopped. Implementation may require international agreements.

Stratospheric Aerosol Injection

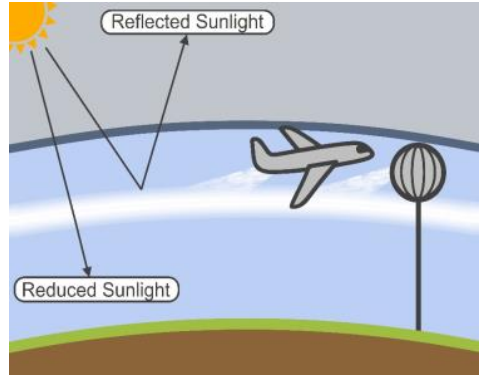

Stratospheric Aerosol Injection involves spreading tiny reflective particles into the stratosphere. The particles reflect some sunlight back into space, rapidly cooling the whole Earth. Sulphate aerosols could be spread using aeroplanes or large balloons tethered to lightweight pipes. Building fleets of aeroplanes or balloons incurs costs. Stratospheric aerosols would make the sky whiter and could affect the ozone layer, rainfall patterns and crop yields. Environmental and local impacts are poorly understood. Large-scale implementation and continuous applications are impacts are poorly understood. Large-scale implementation and continuous applications are
required to maintain the cooling effect. Temperatures would quickly revert to pre-application levels required to maintain the cooling effect. Temperatures would quickly
if stopped. Implementation may require international agreements. 


\subsection{Concept evaluation}

On separated pages respondents evaluate each concept image and description individually in a randomised order (See Supplementary Figure 2) using the measures outlined below in Supplementary

Table 6:

\section{Supplementary Table 6 | Concept evaluation questions}

Item Format Responses

\section{Attribute selection}

Which of the descriptors in the list below do you think applies to [concept name]? Please select as many as apply.

\section{Concept statements}

Please read the statements below and indicate whether you agree or disagree by clicking ONE button beside each statement. ${ }^{b}$

I think [concept name] would help reduce global warming.

I would support small-scale trials of [concept name].

After reading the description I think that I could explain [concept name] to somebody else.
Multiple answer Unknown effects; Risky; Artificial;

(Pick-any) Understandable; Environmentally friendly; Controllable; Long-term sustainability; Quick-fix; Eyesore; Cost effective; Beneficial; Unpredictable ${ }^{\text {a }}$

Single answer Strongly agree; Agree; Neutral; Disagree; (Likert-scale) Strongly disagree

\footnotetext{
${ }^{a}$ Responses order in the attribute selection task are randomised to reduce order effects.

${ }^{\mathrm{b}}$ Item order in the concept statement task are randomised to reduce order effects.
} 


\section{$3.4 \quad$ Further questionnaire items}

After the concept evaluation block, respondents completed further questionnaire items outlined in Supplementary Table 7. Then, participants were asked a series of demographic questions outlined in Supplementary Tables 2-5.

Supplementary Table 7 | Further questionnaire items (UK)

\begin{tabular}{lll}
\hline Item & Format & Responses \\
\hline
\end{tabular}

\section{Prior awareness}

Did you know about any of these proposals before you began this survey?

\section{Ecological concern (NEP scale items)}

Now we would like to ask a few questions about your views on the environment. Please read the statements below and indicate whether you agree or disagree by clicking ONE button beside each statement.

Humans have the right to modify the natural environment to suit their needs.

Humans are severely abusing the environment.

We are approaching the limit of the number of people the earth can support

The balance of nature is very delicate and easily upset.

Humans will eventually learn enough about how nature works to be able to control it.

Single Answer $\quad$ Yes; No
(Pick-one)

Single answer

Strongly agree; Agree; Neutral; Disagree; (Likert-scale) Strongly disagree 


\section{Quantitative Phase - Analysis of Net Positive Variable}

\subsection{Elimination of duplicate measures.}

Following the procedures used in the 2012 study (Wright et al. 2014), we use Kendal Tau-B nonparametric attribute correlations (Supplementary Table 8) to detect and eliminate any overlapping memory structures (Romaniuk 2013). The results presented are the average of six correlation matrixes, one for each climate engineering technique, across the four countries. None of the reported correlations are high. However, three correlations are above 0.35 and thus substantially exceed the average for the attributes involved. This meets the criteria for eliminating attributes to avoid duplicate measurement from overlapping attributes (Romaniuk 2013), and as in the 2012 study (Wright et al. 2014), the attributes unpredictable and beneficial are excluded from analysis.

\section{Supplementary Table 8 | Average Kendall Tau-b Nonparametric Correlations ( $n=2989)$}

\begin{tabular}{|c|c|c|c|c|c|c|c|c|c|c|c|c|}
\hline & Unk & Unp & Ris & Art & Qui & Eye & Und & Ben & Con & Env & Sus & $\operatorname{Cos}$ \\
\hline Unknown effects & & 0.36 & 0.30 & 0.17 & 0.01 & 0.05 & -0.13 & -0.25 & -0.21 & -0.23 & -0.20 & -0.17 \\
\hline Unpredictable* & 0.36 & & 0.37 & 0.20 & 0.04 & 0.07 & -0.14 & -0.25 & -0.22 & -0.22 & -0.20 & -0.16 \\
\hline Risky & 0.30 & 0.37 & & 0.21 & 0.05 & 0.10 & -0.13 & -0.24 & -0.21 & -0.23 & -0.18 & -0.13 \\
\hline Artificial & 0.17 & 0.20 & 0.21 & & 0.11 & 0.14 & -0.03 & -0.12 & -0.06 & -0.13 & -0.10 & -0.07 \\
\hline Quick Fix & 0.01 & 0.04 & 0.05 & 0.11 & & 0.06 & 0.00 & -0.02 & 0.00 & -0.03 & -0.03 & 0.02 \\
\hline Eyesore & 0.05 & 0.07 & 0.10 & 0.14 & 0.06 & & -0.02 & -0.07 & -0.03 & -0.07 & -0.05 & -0.02 \\
\hline Understandable & -0.13 & -0.14 & -0.13 & -0.03 & 0.00 & -0.02 & & 0.25 & 0.23 & 0.23 & 0.19 & 0.12 \\
\hline Beneficial* & -0.25 & -0.25 & -0.24 & -0.12 & -0.02 & -0.07 & 0.25 & & 0.31 & 0.35 & 0.31 & 0.21 \\
\hline Controllable & -0.21 & -0.22 & -0.21 & -0.06 & 0.00 & -0.03 & 0.23 & 0.31 & & 0.28 & 0.25 & 0.18 \\
\hline Env. Friendly & -0.23 & -0.22 & -0.23 & -0.13 & -0.03 & -0.07 & 0.23 & 0.35 & 0.28 & & 0.31 & 0.21 \\
\hline Sustainability & -0.20 & -0.20 & -0.18 & -0.10 & -0.03 & -0.05 & 0.19 & 0.31 & 0.25 & 0.31 & & 0.21 \\
\hline Cost effective & -0.17 & -0.16 & -0.13 & -0.07 & 0.02 & -0.02 & 0.12 & 0.21 & 0.18 & 0.21 & 0.21 & \\
\hline
\end{tabular}

*Unpredictable and Beneficial were both correlated with other attributes and were therefore removed. 


\subsection{Statistical properties of net positive variable}

For each country, a Kolmogorov-Smirnov test rejects the null hypothesis of no difference from a normal distribution. However graphical analysis does show a close approximation to the normal distribution in all countries as shown by histograms (Supplementary Figure 2) and Q-Q Plots (Supplementary Figure 3). Kurtosis of the net positive variable in each country ranges from 0.484 to 0.968 (SE approximately 0.18), while skewness ranges from -0.001 to 0.092 (SE approximately 0.90) (Supplementary Table 9). Although Kurtosis is less than the normal distribution value of 3.0, it is within the range considered acceptable for approximation to a normal distribution. Skewness is not significantly different from zero. The net positive variable is therefore suitable for further analysis using standard statistical tests.

\section{Supplementary Figure 3 | Histogram of Net Positive Measure}
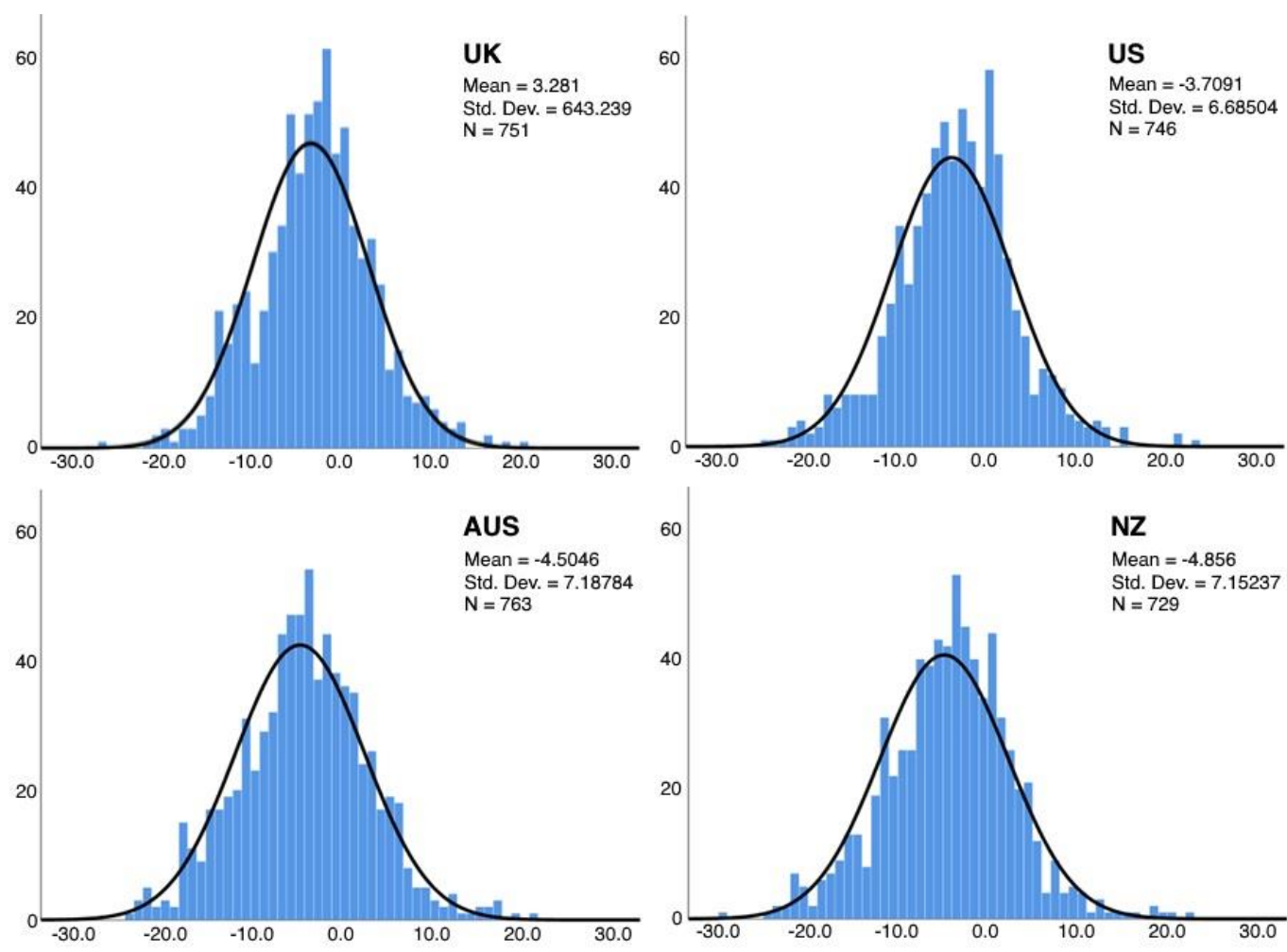


\section{Supplementary Figure 4 | Normal Q-Q Plot of Net Positive Measure}
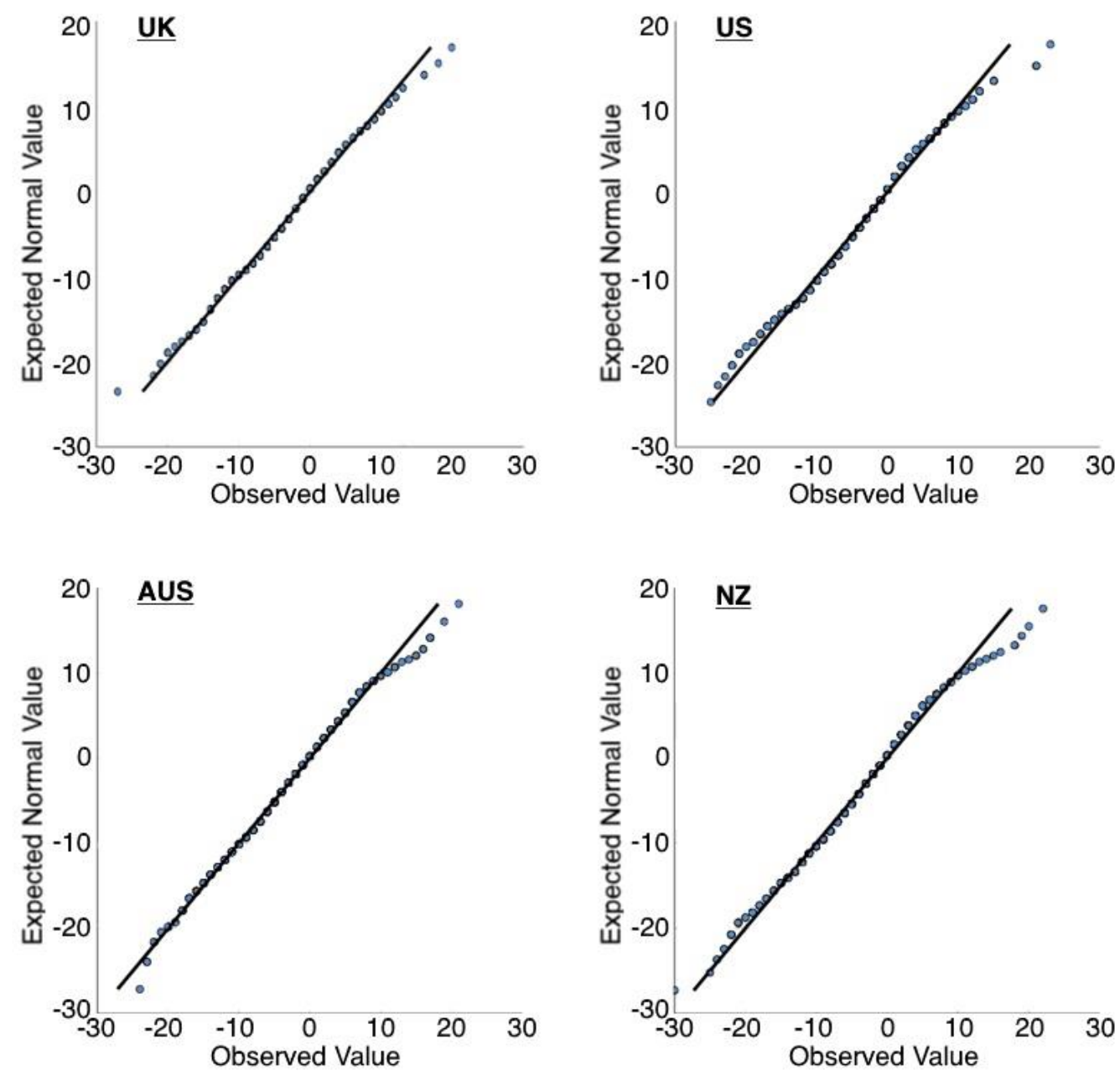

Supplementary Table 9 | Kurtosis and Skewness of the Net Positive Variable

\begin{tabular}{lll}
\hline Sample & Kurtosis & Standard Error \\
\hline UK & .484 & .178 \\
US & .968 & .179 \\
AU & .327 & .177 \\
NZ & .789 & .181 \\
\hline Sample & Skewness & Standard Error \\
\hline UK & .000 & .089 \\
US & .015 & .090 \\
AU & .092 & .089 \\
NZ & -.001 & .091 \\
\hline
\end{tabular}


We next consider univariate tests of associations between the net positive variable and demographic variables, including political party affiliation (Supplementary Table 10). ANOVA is used for all demographic tests except Age, where bivariate correlation is appropriate. Due to the large number of tests we employ the Bonferroni correction to critical p-values. Statistically significant relationships are found with the Age and Political Party variables in all four countries. Age is recorded as year-born and coded in reverse to give the intuitive interpretation of increasing numbers being equivalent to increasing age, indicating older people tend to be more negative about climate engineering than younger people; however, the effect is small as indicated by r-values of less than 0.30 .

Turning to consider political party affiliation, Republicans in the US are more negative towards climate engineering than Democrats. A significant relationship is also found in Australia, UK and NZ where respondents who selected 'Other (Please Specify):' were more negative about climate engineering; however, several of these respondents did not provide a clear affiliation (e.g. "none", "I don't know", "prefer not to say"). A further test for political party excluding the 'Other' category showed no significant relationship in the UK, AU and NZ, although the association between political party and the net positive variable remained statistically significant in the US. Political party was deemed to be unnecessary as a covariate for the principal analyses.

As univariate tests may be subject to omitted variable bias and do not consider interactions between demographic variables, we extend the analysis by jointly estimating demographic effects and 2-way interactions using a general linear model (Supplementary Table 11). Again, we use the Bonferroni correction to critical p-values to account for the large number of statistical tests undertaken. The analysis does not reveal any significant effect of demographics on the net positive variable based on a Bonferroni corrected critical P-Value of .002 (Supplementary Table 11). 


\begin{tabular}{|c|c|c|c|c|c|}
\hline \multicolumn{6}{|c|}{ Supplementary Table $10 \mid$ Univariate Tests for Differences on the Net Positive Variable } \\
\hline & & $\begin{array}{l}\text { Test } \\
\text { statistic }\end{array}$ & $\begin{array}{r}\text { Test } \\
\text { statistic } \\
\text { value } \\
\end{array}$ & P value & $\begin{array}{r}\text { Bonferroni- } \\
\text { corrected } \\
\text { critical P value }\end{array}$ \\
\hline \multicolumn{6}{|l|}{ UK Data } \\
\hline Gender & One Way Anova & $\mathbf{F}_{(.05,1,749)}$ & 0.017 & 0.895 & 0.008 \\
\hline Location & One Way Anova & $\mathbf{F}_{(.05,7,743)}$ & 1.520 & 0.157 & 0.008 \\
\hline Education & One Way Anova & $\mathbf{F}_{(.05,5,745)}$ & 2.357 & 0.039 & 0.008 \\
\hline Household Income & One Way Anova & $\mathbf{F}_{(.05,8,742)}$ & 1.682 & 0.099 & 0.008 \\
\hline Political Party & One Way Anova & $\mathbf{F}_{(.05,5,745)}$ & 4.746 & $<0.001$ & 0.008 \\
\hline Age & Correlation & $\mathbf{r}$ & -0.138 & $<0.001$ & 0.008 \\
\hline \multicolumn{6}{|l|}{ US Data } \\
\hline Gender & One Way Anova & $\mathbf{F}_{(.05,1,745)}$ & 3.453 & 0.064 & 0.008 \\
\hline Location & One Way Anova & $\mathbf{F}_{(.05,7,738)}$ & 0.754 & 0.626 & 0.008 \\
\hline Education & One Way Anova & $\mathbf{F}_{(.05,5,740)}$ & 1.668 & 0.140 & 0.008 \\
\hline Household Income & One Way Anova & $\mathbf{F}_{(.05,10,735)}$ & 0.989 & 0.452 & 0.008 \\
\hline Political Party & One Way Anova & $\mathbf{F}_{(.05,2,739)}$ & 10.079 & $<0.001$ & 0.008 \\
\hline Age & Correlation & $\mathbf{r}$ & -0.295 & $<0.001$ & 0.008 \\
\hline \multicolumn{6}{|l|}{ AU Data } \\
\hline Gender & One Way Anova & $\mathbf{F}_{(.05,1,761)}$ & 1.412 & 0.235 & 0.008 \\
\hline Location & One Way Anova & $\mathbf{F}_{(.05,7,755)}$ & 1.794 & 0.085 & 0.008 \\
\hline Education & One Way Anova & $\mathbf{F}_{(.05,5,757)}$ & 2.001 & 0.076 & 0.008 \\
\hline Household Income & One Way Anova & $\mathbf{F}_{(.05,13,749)}$ & 0.818 & 0.641 & 0.008 \\
\hline Political Party & One Way Anova & $\mathbf{F}_{(.05,3,752)}$ & 6.417 & $<0.001$ & 0.008 \\
\hline Age & Correlation & $\mathbf{r}$ & -0.286 & $<0.001$ & 0.008 \\
\hline \multicolumn{6}{|l|}{ NZ Data } \\
\hline Gender & One Way Anova & $\mathbf{F}_{(.05,1,727)}$ & 0.057 & 0.812 & 0.008 \\
\hline Location & One Way Anova & $\mathbf{F}_{(.05,6,722)}$ & 1.078 & 0.374 & 0.008 \\
\hline Education & One Way Anova & $\mathbf{F}_{(.05,5,723)}$ & 1.329 & 0.250 & 0.008 \\
\hline Household Income & One Way Anova & $\mathbf{F}_{(.05,9,719)}$ & 0.387 & 0.941 & 0.008 \\
\hline Political Party & One Way Anova & $\mathbf{F}_{(.05,4,716)}$ & 4.357 & 0.002 & 0.008 \\
\hline Age & Correlation & $\mathbf{r}$ & -0.208 & $<0.001$ & 0.008 \\
\hline
\end{tabular}




\begin{tabular}{|c|c|c|c|}
\hline \multicolumn{4}{|c|}{$\begin{array}{l}\text { Supplementary Table } 11 \text { | Multivariate Tests for Differences on the Net Positive } \\
\text { Variable }\end{array}$} \\
\hline & F value & $\mathrm{P}$ value & $\begin{array}{r}\text { Bonferroni- corrected } \\
\text { critical P value* }\end{array}$ \\
\hline \multicolumn{4}{|l|}{ UK Data } \\
\hline 1 Intercept & 0.817 & 0.369 & 0.002 \\
\hline 2 Gender & 0.179 & 0.673 & 0.002 \\
\hline 3 Location & 0.400 & 0.903 & 0.002 \\
\hline 4 Education & 0.573 & 0.720 & 0.002 \\
\hline 5 Household Income & 1.056 & 0.393 & 0.002 \\
\hline 6 Political Party & 1.368 & 0.236 & 0.002 \\
\hline 7 Age & 0.060 & 0.807 & 0.002 \\
\hline $2 \times 3$ Interaction & 0.502 & 0.833 & 0.002 \\
\hline $2 \times 4$ Interaction & 0.401 & 0.848 & 0.002 \\
\hline $2 \times 5$ Interaction & 0.369 & 0.937 & 0.002 \\
\hline $2 \times 6$ Interaction & 1.040 & 0.386 & 0.002 \\
\hline $2 \times 7$ Interaction & 0.769 & 0.381 & 0.002 \\
\hline $3 \times 4$ Interaction & 0.850 & 0.704 & 0.002 \\
\hline $3 \times 5$ Interaction & 0.575 & 0.994 & 0.002 \\
\hline $3 \times 6$ Interaction & 0.862 & 0.668 & 0.002 \\
\hline $3 \times 7$ Interaction & 0.530 & 0.812 & 0.002 \\
\hline $4 \times 5$ Interaction & 1.065 & 0.370 & 0.002 \\
\hline $4 \times 6$ Interaction & 1.145 & 0.305 & 0.002 \\
\hline $4 \times 7$ Interaction & 0.180 & 0.970 & 0.002 \\
\hline $5 \times 6$ Interaction & 0.724 & 0.868 & 0.002 \\
\hline $5 \times 7$ Interaction & 0.629 & 0.753 & 0.002 \\
\hline $6 \times 7$ Interaction & 1.769 & 0.134 & 0.002 \\
\hline \multicolumn{4}{|l|}{ US Data } \\
\hline 1 Intercept & 0.242 & 0.624 & 0.002 \\
\hline 2 Gender & 0.877 & 0.352 & 0.002 \\
\hline 3 Location & 1.070 & 0.384 & 0.002 \\
\hline 4 Education & 0.597 & 0.702 & 0.002 \\
\hline 5 Household Income & 0.866 & 0.566 & 0.002 \\
\hline 6 Political Party & 0.665 & 0.516 & 0.002 \\
\hline 7 Age & 0.396 & 0.529 & 0.002 \\
\hline $2 \times 3$ Interaction & 1.062 & 0.387 & 0.002 \\
\hline $2 \times 4$ Interaction & 0.651 & 0.661 & 0.002 \\
\hline $2 \times 5$ Interaction & 1.038 & 0.410 & 0.002 \\
\hline $2 \times 6$ Interaction & 0.558 & 0.573 & 0.002 \\
\hline $2 \times 7$ Interaction & 1.304 & 0.254 & 0.002 \\
\hline $3 \times 4$ Interaction & 0.902 & 0.622 & 0.002 \\
\hline $3 \times 5$ Interaction & 1.246 & 0.105 & 0.002 \\
\hline $3 \times 6$ Interaction & 0.855 & 0.609 & 0.002 \\
\hline $3 \times 7$ Interaction & 1.488 & 0.169 & 0.002 \\
\hline $4 \times 5$ Interaction & 1.367 & 0.069 & 0.002 \\
\hline $4 \times 6$ Interaction & 1.608 & 0.110 & 0.002 \\
\hline $4 \times 7$ Interaction & 1.239 & 0.289 & 0.002 \\
\hline $5 \times 6$ Interaction & 1.252 & 0.211 & 0.002 \\
\hline $5 \times 7$ Interaction & 0.459 & 0.916 & 0.002 \\
\hline $6 \times 7$ Interaction & 1.265 & 0.283 & 0.002 \\
\hline \multicolumn{4}{|l|}{ AU Data } \\
\hline 1 Intercept & 1.000 & 0.325 & 0.002 \\
\hline 2 Gender & 0.122 & 0.727 & 0.002 \\
\hline 3 Location & 1.739 & 0.103 & 0.002 \\
\hline 4 Education & 2.679 & 0.022 & 0.002 \\
\hline 5 Household Income & 1.081 & 0.373 & 0.002 \\
\hline 6 Political Party & 2.095 & 0.103 & 0.002 \\
\hline 7 Age & 3.351 & 0.068 & 0.002 \\
\hline $2 \times 3$ Interaction & 1.981 & 0.056 & 0.002 \\
\hline $2 \times 4$ Interaction & 2.536 & 0.028 & 0.002 \\
\hline $2 \times 5$ Interaction & 0.948 & 0.503 & 0.002 \\
\hline $2 \times 6$ Interaction & 4.195 & 0.006 & 0.002 \\
\hline $2 \times 7$ Interaction & 1.840 & 0.176 & 0.002 \\
\hline $3 \times 4$ Interaction & 1.100 & 0.325 & 0.002 \\
\hline
\end{tabular}




\begin{tabular}{|c|c|c|c|}
\hline $3 \times 5$ Interaction & 1.181 & 0.151 & 0.002 \\
\hline $3 \times 6$ Interaction & 1.121 & 0.328 & 0.002 \\
\hline $3 \times 7$ Interaction & 0.911 & 0.498 & 0.002 \\
\hline $4 \times 5$ Interaction & 0.829 & 0.818 & 0.002 \\
\hline $4 \times 6$ Interaction & 1.681 & 0.057 & 0.002 \\
\hline $4 \times 7$ Interaction & 1.696 & 0.134 & 0.002 \\
\hline $5 \times 6$ Interaction & 1.099 & 0.319 & 0.002 \\
\hline $5 \times 7$ Interaction & 1.272 & 0.227 & 0.002 \\
\hline $6 \times 7$ Interaction & 0.978 & 0.403 & 0.002 \\
\hline \multicolumn{4}{|l|}{ NZ Data } \\
\hline 1 Intercept & 17.921 & 0.060 & 0.002 \\
\hline 2 Gender & 0.001 & 0.976 & 0.002 \\
\hline 3 Location & 0.665 & 0.678 & 0.002 \\
\hline 4 Education & 0.639 & 0.671 & 0.002 \\
\hline 5 Household Income & 0.430 & 0.918 & 0.002 \\
\hline 6 Political Party & 1.316 & 0.269 & 0.002 \\
\hline 7 Age & 0.497 & 0.481 & 0.002 \\
\hline $2 \times 3$ Interaction & 0.709 & 0.642 & 0.002 \\
\hline $2 \times 4$ Interaction & 2.033 & 0.073 & 0.002 \\
\hline $2 \times 5$ Interaction & 1.685 & 0.090 & 0.002 \\
\hline $2 \times 6$ Interaction & 1.740 & 0.140 & 0.002 \\
\hline $2 \times 7$ Interaction & 1.264 & 0.261 & 0.002 \\
\hline $3 \times 4$ Interaction & 0.911 & 0.605 & 0.002 \\
\hline $3 \times 5$ Interaction & 0.867 & 0.730 & 0.002 \\
\hline $3 \times 6$ Interaction & 0.943 & 0.543 & 0.002 \\
\hline $3 \times 7$ Interaction & 0.337 & 0.917 & 0.002 \\
\hline $4 \times 5$ Interaction & 0.997 & 0.481 & 0.002 \\
\hline $4 \times 6$ Interaction & 0.727 & 0.799 & 0.002 \\
\hline $4 \times 7$ Interaction & 1.878 & 0.097 & 0.002 \\
\hline $5 \times 6$ Interaction & 0.920 & 0.606 & 0.002 \\
\hline $5 \times 7$ Interaction & 1.428 & 0.173 & 0.002 \\
\hline $6 \times 7$ Interaction & 0.548 & 0.700 & 0.002 \\
\hline
\end{tabular}




\begin{tabular}{|c|c|c|c|c|}
\hline \multicolumn{5}{|c|}{$\begin{array}{l}\text { Supplementary Table } 12 \text { | Tests for Differences of CDR and SRM Evaluations Between } \\
\text { Countries }\end{array}$} \\
\hline & Test & $\begin{array}{l}\text { Test } \\
\text { statistic }\end{array}$ & $\begin{array}{r}\text { Test } \\
\text { statistic } \\
\text { value } \\
\end{array}$ & $\begin{array}{r}\mathbf{P} \\
\text { value }\end{array}$ \\
\hline \multicolumn{5}{|c|}{ Homogeneity of Variance Between } \\
\hline CDR Net Positive Variable & Levene Statistic ${ }^{\mathrm{a}}$ & $\boldsymbol{W}_{(.05,3,2985)}$ & 4.157 & 0.006 \\
\hline SRM Net Positive Variable & Levene Statistic & $\boldsymbol{W}_{(.05,3,2985)}$ & 3.234 & 0.021 \\
\hline \multicolumn{5}{|l|}{ Variance Between Countries } \\
\hline CDR Net Positive Variable & One Way Anova & $\mathbf{F}_{(.05,3,2985)}$ & 3.659 & 0.012 \\
\hline \multirow[t]{2}{*}{ SRM Net Positive Variable } & One Way Anova & $\mathbf{F}_{(.05,3,2985)}$ & 13.464 & $<0.001$ \\
\hline & Test & $\begin{array}{r}\text { Mean } \\
\text { Difference }\end{array}$ & $\begin{array}{r}\text { Std. } \\
\text { Error }\end{array}$ & $\begin{array}{r}\mathbf{P} \\
\text { value }\end{array}$ \\
\hline \multicolumn{5}{|l|}{ Post-Hoc Test for Multiple } \\
\hline $\mathrm{UK}^{\mathrm{b}} \times \mathrm{US}^{\mathrm{c}}$ & Games Howell & 0.570 & 0.211 & 0.035 \\
\hline UK x AU & Games Howell & 0.576 & 0.217 & 0.041 \\
\hline UK x NZ & Games Howell & 0.622 & 0.227 & 0.031 \\
\hline US x AU & Games Howell & 0.005 & 0.211 & 1.000 \\
\hline US X NZ & Games Howell & 0.052 & 0.221 & 0.995 \\
\hline $\mathrm{AU} \times \mathrm{NZ}$ & Games Howell & 0.047 & 0.227 & 0.997 \\
\hline \multicolumn{5}{|l|}{ Post-Hoc Test for Multiple } \\
\hline UK x US & Games Howell & -0.142 & 0.194 & 0.883 \\
\hline $\mathrm{UK} \times \mathrm{AU}$ & Games Howell & 0.648 & 0.200 & 0.007 \\
\hline UK x NZ & Games Howell & 0.953 & 0.197 & $<0.001$ \\
\hline $\mathrm{US} \times \mathrm{AU}$ & Games Howell & 0.790 & 0.203 & 0.001 \\
\hline US X NZ & Games Howell & 1.095 & 0.200 & $<0.001$ \\
\hline AU x NZ & Games Howell & 0.305 & 0.206 & 0.451 \\
\hline
\end{tabular}

\footnotetext{
${ }^{a}$ Here we report the Levene Statistic for the CDR and SRM Variables based on the Mean. Mean difference is calculated as mean ${ }^{\mathrm{b}}-$ mean $^{\mathrm{c}}$.
} 


\section{Quantitative Phase - Construction of Concept Maps}

To enable replication, we provide an illustration of the development of the concept maps for the UK data. These require the tabulation of the retained attribute associations shown in Supplementary Table 13 followed by a chi-square calculation of expected association counts for each attribute for each concept. The difference between actual and expected association counts is converted into percentages in Supplementary Table 14, and then given a graphical presentation in Supplementary Figure 4 below. For completeness, we present graphical presentations for the, US, Australia and NZ in Supplementary Figures 5 - 7.

\section{Supplementary Table 13 | Final Attribute Counts (UK Data)}

\begin{tabular}{|c|c|c|c|c|c|c|c|}
\hline & BECCS & $D A C S S$ & $E W$ & $M C B$ & SAI & $M I S$ & TOTAL \\
\hline Unknown effects & 252 & 268 & 324 & 359 & 407 & 383 & 1993 \\
\hline Risky & 185 & 183 & 239 & 263 & 389 & 323 & 1582 \\
\hline Artificial & 134 & 161 & 144 & 228 & 253 & 256 & 1176 \\
\hline Eyesore & 92 & 117 & 62 & 51 & 60 & 85 & 467 \\
\hline Quick-fix & 73 & 85 & 85 & 109 & 109 & 84 & 545 \\
\hline Understandable & 183 & 162 & 151 & 101 & 82 & 92 & 771 \\
\hline Controllable & 155 & 163 & 131 & 110 & 55 & 68 & 682 \\
\hline Environmentally friendly & 176 & 146 & 161 & 97 & 51 & 89 & 720 \\
\hline Long-term sustainability & 172 & 148 & 135 & 75 & 56 & 87 & 673 \\
\hline Cost effective & 107 & 80 & 105 & 56 & 45 & 60 & 453 \\
\hline TOTAL & 1529 & 1513 & 1537 & 1449 & 1507 & 1527 & 9062 \\
\hline$\%$ & $17 \%$ & $17 \%$ & $17 \%$ & $16 \%$ & $17 \%$ & $17 \%$ & \\
\hline
\end{tabular}


Supplementary Table 14 | Percentage Deviations from Expected Attribute Counts (UK Data)

\begin{tabular}{|c|c|c|c|c|c|c|c|}
\hline & $B E C C S$ & $D A C S S$ & $E W$ & $M C B$ & $S A I$ & MIS & $\begin{array}{r}\text { Average } \\
\text { (absolute values) }\end{array}$ \\
\hline Unknown effects & $-6 \%$ & $-4 \%$ & $-1 \%$ & $3 \%$ & $5 \%$ & $3 \%$ & $4 \%$ \\
\hline Risky & $-5 \%$ & $-5 \%$ & $-2 \%$ & $1 \%$ & $8 \%$ & $4 \%$ & $4 \%$ \\
\hline Artificial & $-4 \%$ & $-2 \%$ & $-4 \%$ & $3 \%$ & $4 \%$ & $4 \%$ & $3 \%$ \\
\hline Eyesore & $1 \%$ & $3 \%$ & $-1 \%$ & $-2 \%$ & $-1 \%$ & $0 \%$ & $1 \%$ \\
\hline Quick-fix & $-1 \%$ & $0 \%$ & $0 \%$ & $2 \%$ & $1 \%$ & $-1 \%$ & $1 \%$ \\
\hline Understandable & $3 \%$ & $2 \%$ & $1 \%$ & $-2 \%$ & $-3 \%$ & $-2 \%$ & $2 \%$ \\
\hline Controllable & $3 \%$ & $3 \%$ & $1 \%$ & $0 \%$ & $-4 \%$ & $-3 \%$ & $2 \%$ \\
\hline Environmentally friendly & $4 \%$ & $2 \%$ & $3 \%$ & $-1 \%$ & $-5 \%$ & $-2 \%$ & $3 \%$ \\
\hline Long-term sustainability & $4 \%$ & $2 \%$ & $1 \%$ & $-2 \%$ & $-4 \%$ & $-2 \%$ & $3 \%$ \\
\hline Cost effective & $2 \%$ & $0 \%$ & $2 \%$ & $-1 \%$ & $-2 \%$ & $-1 \%$ & $1 \%$ \\
\hline
\end{tabular}




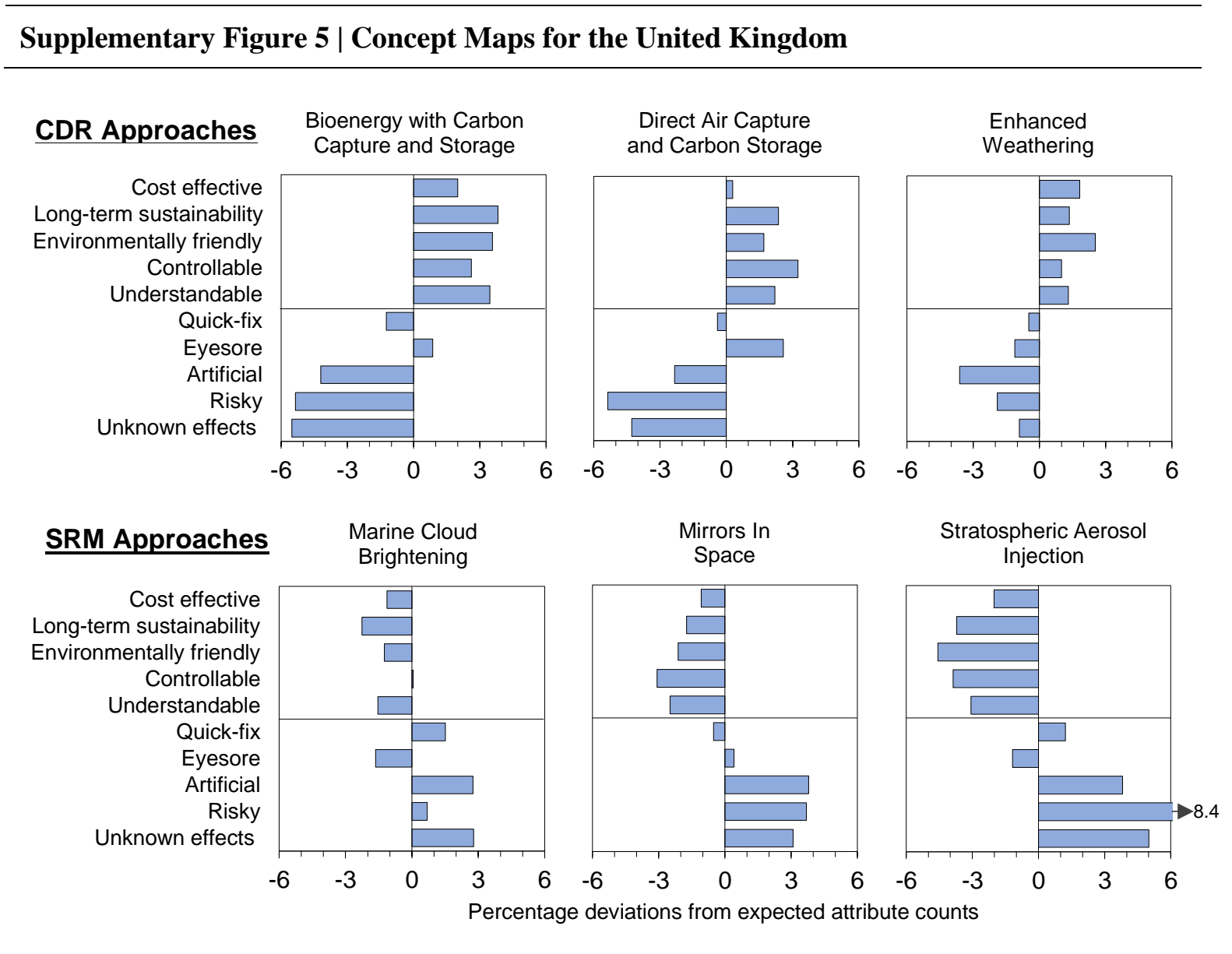

\section{Supplementary Figure 6 | Concept maps for the United States}
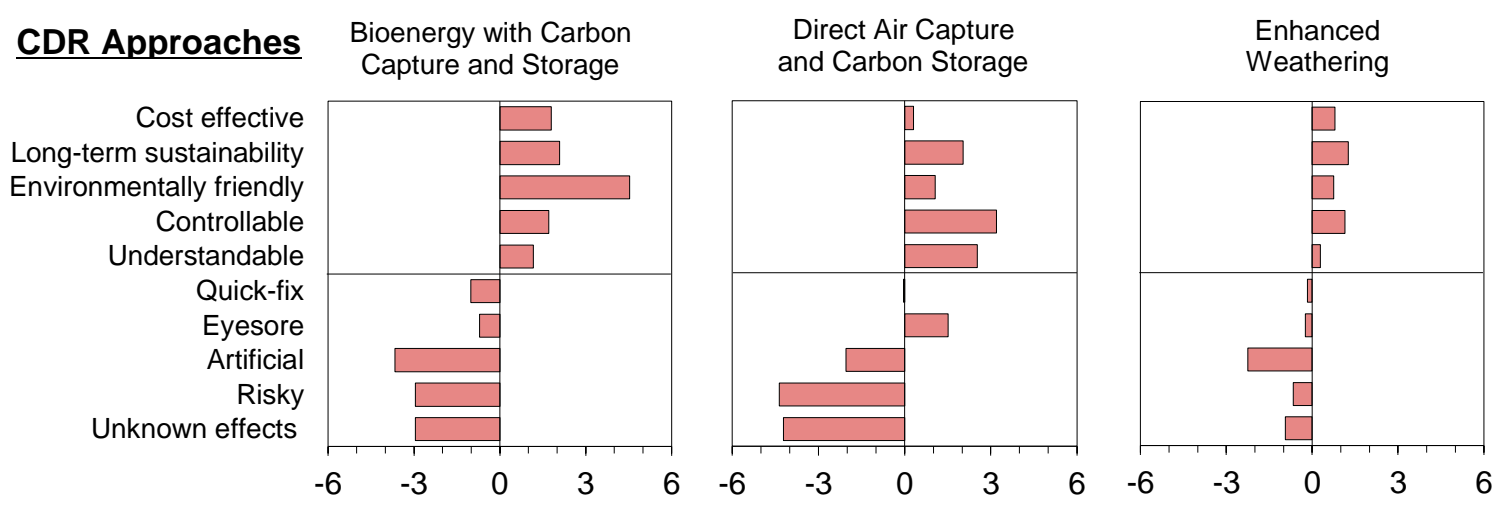

\section{SRM Approaches}

Marine Cloud Brightening
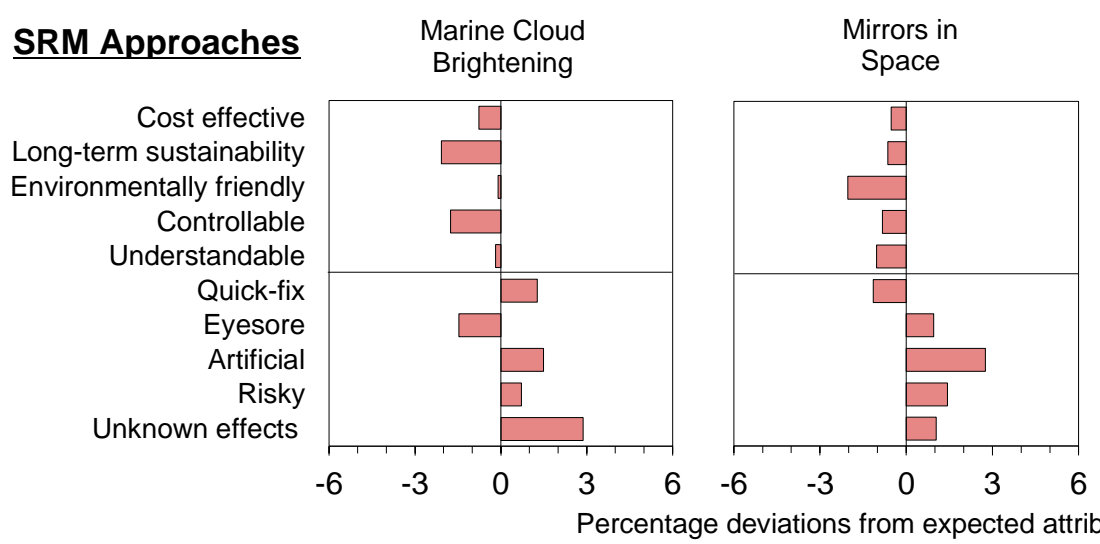

Stratospheric Aerosol Injection

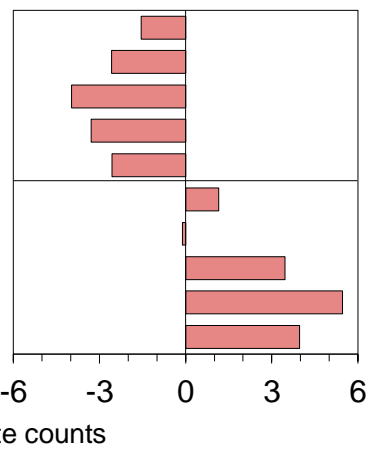




\section{Supplementary Figure 7 | Concept maps for Australia}
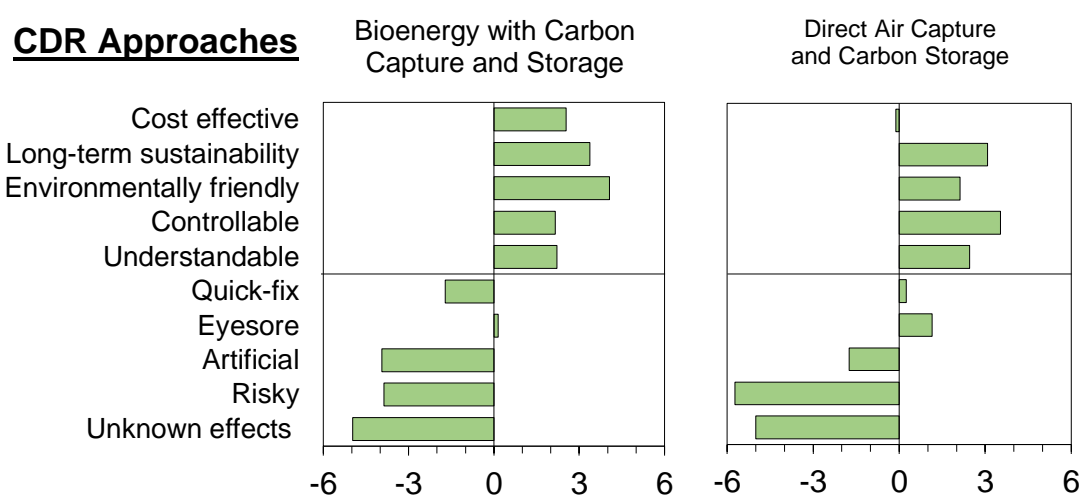

Marine Cloud Brightening

\section{SRM Approaches}

Cost effective Long-term sustainability Environmentally friendly Controllable Understandable Quick-fix Eyesore Artificial Risky Unknown effects
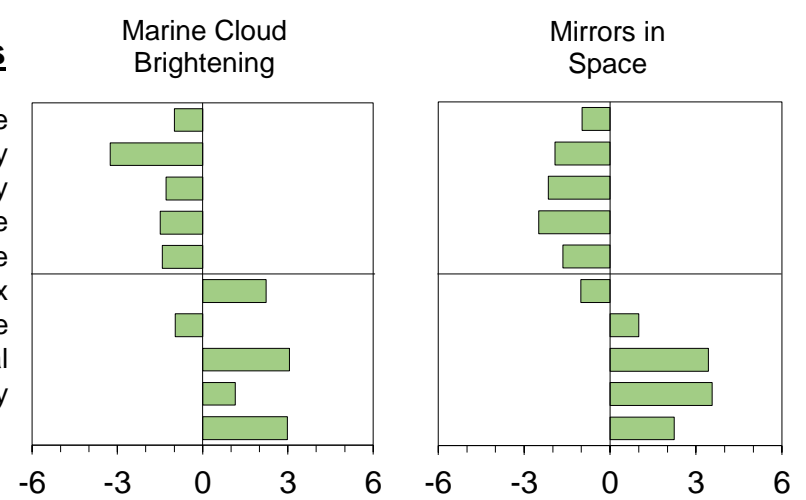

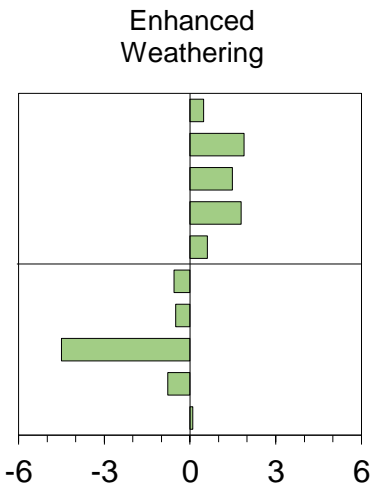

Percentage deviations from expected attribute counts

Stratospheric Aerosol Injection

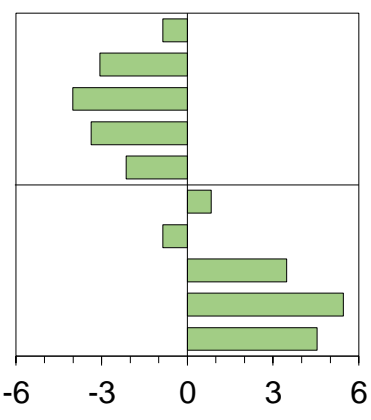

\section{Supplementary Figure 8 | Concept maps for New Zealand}
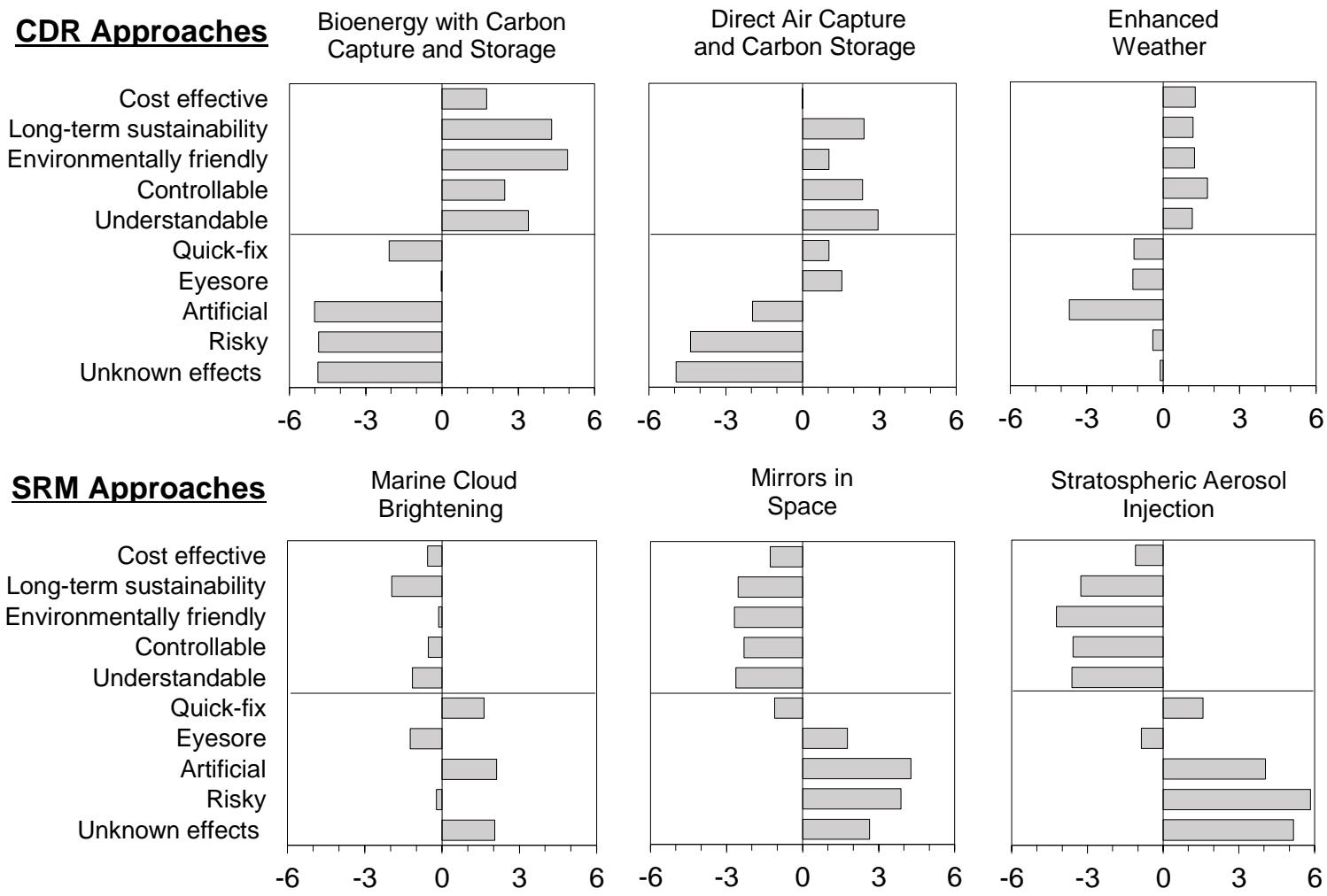

Stratospheric Aerosol Injection

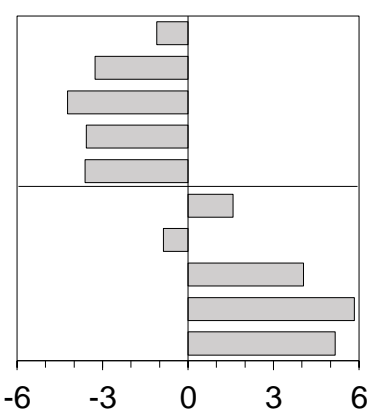

Percentage deviations from expected attribute counts 


\section{Supplementary References (see main manuscript other references)}

1. https://www.ons.gov.uk/peoplepopulationandcommunity/populationandmigration/populatione stimates/datasets/2011 censuspopulationestimatesbysingleyearofageandsexforlocalauthoritiesi ntheunitedkingdom

2. https://webarchive.nationalarchives.gov.uk/20160108132257/http://www.ons.gov.uk/ons/dcp 171778_292378.pdf

3. https://www.ons.gov.uk/file?uri=/peoplepopulationandcommunity/personalandhouseholdfina nces/incomeandwealth/adhocs/009772grosshouseholdincomeukfinancialyearending2018/gros sbandedincome1718.xls

4. https://d25d2506sfb94s.cloudfront.net/cumulus_uploads/document/rrlh8uvy0x/TheTimes_18 1119_VI_Trackers_bpc_w.pdf

5. https://factfinder.census.gov/faces/tableservices/jsf/pages/productview.xhtml?

6. https://www.census.gov/data/tables/time-series/demo/income-poverty/cps-finc.html

7. http://cdn.cnn.com/cnn/2018/images/10/09/rel9b.-.2018.midterms.pdf

8. https://auth.censusdata.abs.gov.au/webapi/jsf/tableView/tableView.xhtml\#।

9. https://www.essentialvision.com.au/wp-content/uploads/2018/12/Essential-Report041218.pdf

10. http://nzdotstat.stats.govt.nz/wbos/Index.aspx?DataSetCode=TABLECODE8001

11. http://archive.stats.govt.nz/Census/2013-census/profile-and-summary-reports/quickstatsabout-a-place.aspx?request_value $=13067 \&$ tabname $=$

12. http://archive.stats.govt.nz/Census/2013-census/profile-and-summary-reports/quickstatsincome.aspx

13. http://archive.stats.govt.nz/ /media/Statistics/Census/2013\%20Census/profile-and-summaryreports/quickstats-about-income/quickstats-income-tables.xls

14. https://www.colmarbrunton.co.nz/wp-content/uploads/2018/12/Prelim_24-28-November2018_1-NEWS-Colmar-Brunton-Poll-report-.pdf 